مجلة جامعة الملك عبدالعزيز: الآداب والعلوم الانسانية، م29ع3 ص ص: 561- 593 (2021م) DOI:10.4197/Art.29-3.20

\title{
متطلبات تطبيق إدارة رأس المال الفكري لدى طلاب جامعة المجمعة من وجهة نظر القيادات الأكاديمية
}

\author{
د. نجلاء عمر صالح العُمري

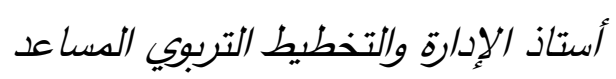 \\ جامعة الإمام محمد بن سعود الإسلامية -كلية التربية الادرولية

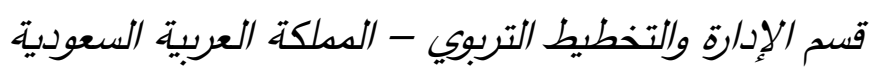 \\ noalomary@imamu.edu.sa :بريد إلكتروني
}

مستخص • يهدف هذا البحث إلى التعرف على المتطلبات البشرية والتتظيمية والمادية لتطبيق إدارة رأس المال الفكري لاى طلبة جامعة المجمعة من وجهة نظر القيادات الأكاديمية. ولتحقيق أهداف البحث قامت الباحثة باستخدام المنهج

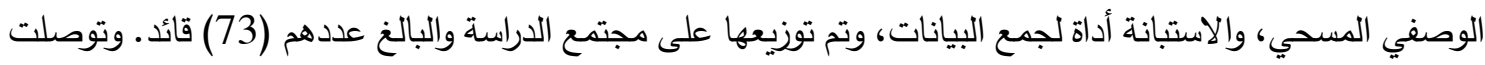
الدراسة إلى عدد من النتائج، من أبرزها: - - أن جميع متطلبات تطبيق إدارة رأس المال الفكري بالجامعة (متطلبات بشرية، متطلبات تنظيمية، متطلبات مادية) هام توافرها بدرجة كبيرة. - عدم وجود فروق ذات دلالة إحصائية بين متوسطات استجابات أفراد عينة الدراسة حول أهمية توافر جميع

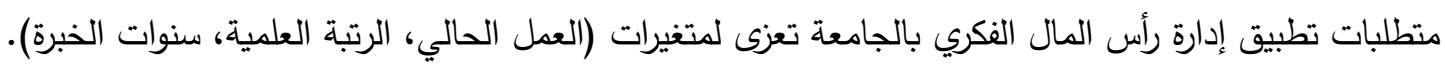
وقد أوصت الدراسة: 1. على الجامعة استثمار وتفعيل رأس المال الفكري الذي يمتلكه طلابها بعد التعرف عليه وتقييمه واستيعابه من خلال تطوير هياكلها لإكسابها مصادر اضافية. 2. على إدارة ضمان الجودة بالجامعة الإشراف على ابداعات وبحوث الطلاب وتقييمها وتحسين نوعيتها للاستفادة منها في تطوير الاداء بالجامعة، وتثجيعهم على المشاركة بالمؤتمرات المحلية والعالمية. 3. العمل على ازالة كافة المعوقات والمشكلات التي تعوق تطبيق ادارة راس الجال المال الفكري لدى الطلاب واستثماره

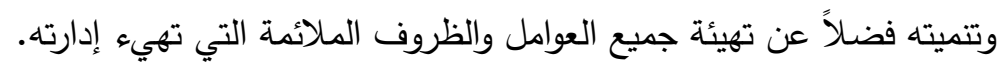

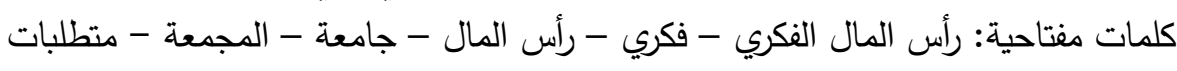

والمنافسة الحادة للمؤسسات؛ تكمن أهمية الاهتمام المقدمة

بالعنصر البشري كأحد متطلبات التنمية للمؤسسات لما يتضمنه من عناصر التميز والإبداع والتمكين. الأمر الذي أدى إلى أن تعمل المؤسسات في ظل
في ظل التطورات والتغيرات السريعة التي يشهدها العالم في عصر العولمة، والتغيرات وثورة الاتصالات، وثورة المعلومات، وثورة التكنولوجيا، والثورة المعرفية، 
والتغيرات المتسارعة، وفي هذا السياق يشير (محد والزائدي،2015م،ص5) إلى أن رأس المال الفكري يتضمن قدرات تتظيمية ومعرفية وابتكارية تثكل أهم عناصر القيمة والتميز للمؤسسات التعليمية في القرن الحادي والعشرين وبخاصة التحول نحو المجتمعات والاقتصاديات كثيفة المعرفة والإبداع. وتأسيسًا على ما سبق يتضح أن الجامعات كمؤسسات تعليمية تمتلك رأس مال فكري تتعدد أشكاله ومصادره، وتتوقف فاعليتها في تحقيق أهدافها وجودة أدائها على لى قدرتها على إدارة واستثمار هذا الرأس مال الفكري

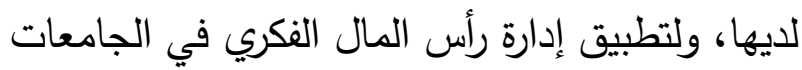
السعودية يستلزم توفير متطلباتها.

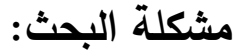
لما للتعليم العالي من مكانة كبيرة وأثر واضح في تأهيل وتوجيه العنصر البشري كأحد مدخلات ومخرجات العملية التعليمية، لذا لا بد من الاهتمام على المتغيرات التي من شأنها أن تساهم في نجاحها وخاصة في ظل المنافسة بين الجامعات السعودية، وسعي كل منها لاستقطاب أفضل الموارد البشرية كأحد منسوبيها، لذلك وجب عليها اسناد قدراتها

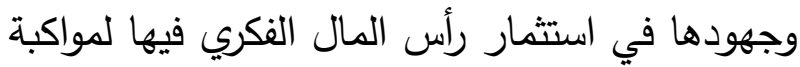
التغيرات المتسارعة والمستمرة. فالعنصر البشري هو مصدر التخطيط، والإبداع والابتكار، فينبغي للجامعات إعادة النظر في كيفية إدارتها، من خلال تفعيلها لخدمة البحث العلمي، وبناء شبكة معلومات داخلية لمهارات ومعارف منسوبي
أجواء تنافسية، كما دفعها لتكوين رؤية واضحة لتجويد أدائها وخدماتها، ووضع استراتيجيات كفيلة ببقائها وتطورها ونهوضها، وإعادة تقييم موجوداتها المادية والمعرفية (الراشدي،2019م،صونائ142) والجامعات كغيرها من المؤسسات التربوية أدركت أن من واجبها المحافظة على المعرفة، ومعرفة كيفية إدارتها واستخدامها، من خلال اكتثاف الكفاءات البشرية الميزة والعمل على استقطابهم من أجل تحقيق الميزة التنافسية. وفي عام 1960 كان الظهور الفعلي لما يسمى بـ "رأس المال البشري" حيث أصبح المكون البشري وما يملكه من مهارات وخبرات ومعارف، العنصر الأساسي في تطور ونجاح المنظمات، كما اعتبر موردًا جوهريًا لا تستطيع أي منظمة من لنا المنظمات الاستغناء عنه (قثقش،2014م). ونظرًا لأهمية رأس المال الفكري باعتباره أكثر الأصول قيمة في القرن الحادي والعشرين، فهو يمثل قوى علمية قادرة على إدخال تعديلات جوهرية في أعمال المؤسسات، كما يعد من أهم المؤشرات التي تعكس

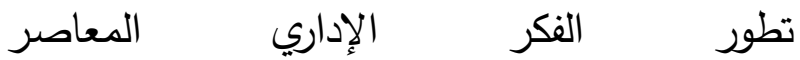
(عبدالحميد،2014م،صنا131)، حيث يفوق رأس الردي المال الفكري في أهميته كل من رأس المال النقدي ورأس المال المادي في تحقيق الكفاءة وتوليد القيمة المضافة، ومن ثم رفع القدرة التنافسية التي تمكن

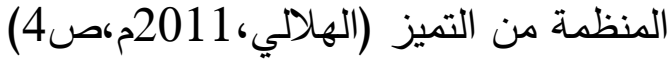
ويمكن للجامعات من خلال رأس المال الفكري تحقيق الإبداع والتميز وزيادة قدرتها على مواجهة التحديات 
ومن هنا فإن ذلك يدعو إلى تطوير رأس المال الفكري في الجامعات السعودية، ولتطبيق إدارة رأس المال الفكري في الجامعات السعودية يستلزم توفير متطلباتها، ومن هنا تكمن أهمية هذه الدراسة في معرفة المتطلبات (التنظيمية، المادية، والبشرية) لتطبيق إدارة

رأس المال الفكري في جامعة المجمعة.

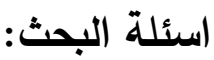

1. ما المتطلبات التظظيمية لتطبيق إدارة رأس المال الفكري لاى طلبة جامعة المجمعة من وجهة نظر

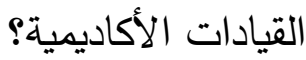
2. ما المتطلبات المادية لتطبيق إدارة رأس المال الفكري لاى طلبة جامعة المجمعة من وجهة نظر عينة

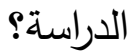

3. ما المتطلبات البشرية لتطبيق إدارة رأس المال الفكري لدى طلبة جامعة المجمعة من وجهة نظر عينة

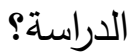
4. هل هناك فروق ذات دلالة إحصائية بين عينة الدراسة تعزى إلى متغير (العمل الحالي، الرتبة

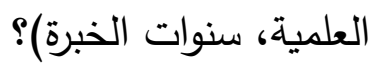

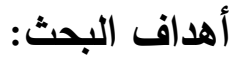

يهاف البحث بثكل رئيس إلى تحديد متطلبات تطبيق إدارة رأس المال الفكري لاى طلبة جامعة المجمعة من وجهة نظر القيادات الأكاديمية من خلال

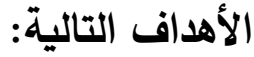

الجامعة من خلال رأس المال التتظيمي، والإفادة من التجارب الدولية، من خلال عمل توازن كافة الجوانب

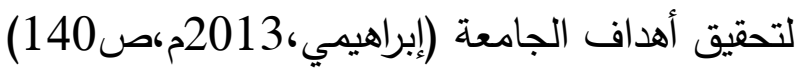
وقد نتجت دراسة (القبلي،2015م) إلى أن ممارسة قيادات كليات التعليم العالي الأهلي بمدينة الرياض

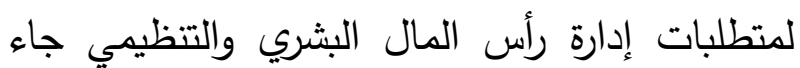
بدرجة متوسطة. وقد أوصت دراسة كل من منوسطه، (الهلالي،2011م)، وكوركولس(2013)، ورودريجو وهيلينا(2015م) بإدارة رأس المال الفكري في الجامعات، والتأكيد على ودى ودئ ضرورة الاهتمام بإدارة رأس المال الفكري، وأن يكون أحد معايير اختيار القيادات الأكاديمية الاهتمام به وقدرتهم على إدارته باعتباره أداة استراتيجية لمواجهة تحديات المستقبل. وقد نتجت دراسة (قرني والعتيقي،2012م) إلى ضعف الجهد المنظم والمخطط لإدارة رأس المال الفكري في الجامعات، وأوصت بالاهتمام برأس المال البشري والعمل على استقطابه، وتفعيل دور رأس المال

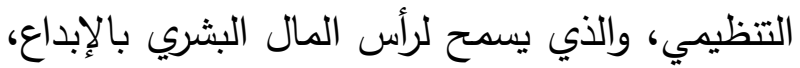
وضرورة قياس رأس المال الفكري والافصاح عنه. وقد بينت دراسة (العجمي وبدارنة،2010م) أن الجامعات لا تتبنى استراتيجيات للمحافظة على رأس المال الفكري وإدارته وتطويره، وأوصت بضرورة اهتمام الجامعات بمكونات رأس المال الفكري، واعتبارها وحدة 
1. التعرف على أبرز المتطلبات البشرية لتطبيق إدارة مصطلحات البحث: رأس المال الفكري لاى طلبة جامعة المجمعة من رأس المال الفكري: القدرة الذهنية لدى الموارد البشرية ممثلة في الطاقات وجهة نظر القيادات الأكاديمية. 2. الكثف عن أبرز المتطلبات التنظيمية لتطبيق والأفكار والكفاءات القادرة على توليد الطاقات والرؤية إدارة رأس المال الفكري لاى طلبة جامعة المجمعة من والأفكار والقدرات المتعلقة في الأنشطة والعمليات الاستراتيجية التي تضمن للمنظمة امتلاك الميزة

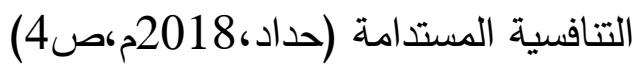
إجرائياً:

نخبة من الطلبة بالجامعة الذين لديهم القدرات المعرفية

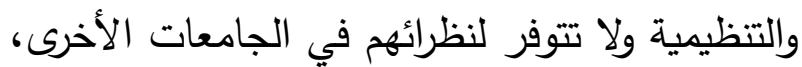
والقادرين على انتاج أفكار جديدة وحيادية من أجل تطوير وتوسيع الجامعة وتحقق لها عوائد مالية ومعنوية تميزها عن الجامعات الأخرى.

إدارة رأس المال الفكري:

مجموعة العمليات التي تمارسها المؤسسات التعليمية لتوظيف مهارات وخبرات ومعارف العاملين بها بما يمكنها من أن تبتكر القيمة المضافة للعملية التعليمية وتحقيق أهدافها ورفع جودة أدائها وتميزها (الراشدي،2017م،صنيق إجرائياً: الممارسات والعمليات التي تتم داخل جامعة المجمعة لتوظيف مهارات وخبرات ومعارف الطلبة داخلها، من خلال التجربة العملية والابتكار، والاستمرار لتحقيق وديق التميز التنافسي لديها. وجهة نظر عينة الدراسة. 3. تحديد أبرز المتطلبات المادية لتطبيق إدارة رأس المال الفكري لاى طلبة جامعة المجمعة من وجهة نظر عينة الدراسة.

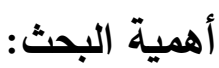
يكتسب هذا البحث أهميته من: 1. الإسهام في معرفة متطلبات تطبيق إدارة رأس المال الفكري لاى طلبة جامعة المجمعة. 2. تسليط الضوء على موضوع "متطلبات تطبيق إدارة رأس المال الفكري في جامعة المجمعة" إذ تعاني المكتبة العربية بشكل عام من قلة الدراسات في مجال إدارة رأس المال الفكري، كما تأتي استكمالًا لجهود الباحثين في هذا المجال. 3. مساهمة هذه الدراسة في إثراء الجانب المعرفي، هدال والذي قد يساعد الباحثين في مجال إدارة رأس المال الفكري في الجامعات. 4. قد تساعد نتائج هذه الدراسة الجهات المسئولة عن تخطيط التعليم العالي إلى تلبية متطلبات إدارة رأس لدأس المال الفكري في الجامعات. 
ومن هذا تعرفها الباحثة إجرائيًا أنه مجموعة مايمتلكه الطلبة في الجامعة من المهارات والخبرات والمشاعر والاتجاهات و والعلاقات والتتظيمات والمعارف واستراتيجيات العمل والتي تساهم في تحقيق أهداف الجامعة ورفع جودة أدائها وتميزها. ويمكن تعريف إدارة رأس المال الفكري بأنها الإدارة الفاعلة لرأس المال الفكري والتي تستطيع توجيه موجوداتها الفكرية والإبداع والتميز وتكون لديها القدرة على استقطاب ذوي المهارات والمعارف وجذبهم للعمل

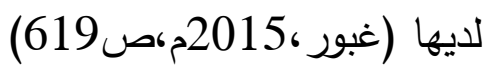
وتعرفها الباحثة إجرائيًا بأنها مجموعة من سياسات العمل التنافسية الداعمة للثقافة التنظيمية للجامعة والتي تمارسها بيئة تنظيمية تعليمية مناسبة، في ضوء نظم فعالة لرفع كفاءات الموارد البشرية، ولتوظيف مهارات وخبرات الطلبة بما يمكنهم من ابتكار القيمة المضافة للعملية التعليمية وتحقيق أهداف الجامعة

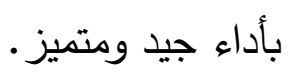

أهمية إدارة رأس المال الفكري: تكمن أهمية إدارة رأس المال الفكري في الجامعات

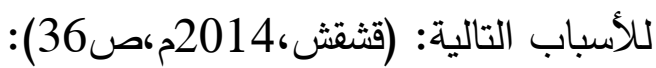
- أن الإدارة الفاعلة لرأس المال الفكري قد تكون المحدد النهائي لأداء الجامعة، إذ أن الجامعة التي لرأي

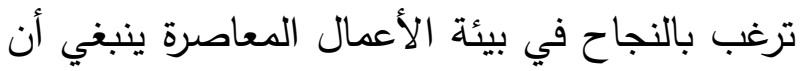
تقوم باستثمارات مناسبة للأصول الفكرية التي تمتلك بكاحك أفرادًا يتمتعون بقدرات ومهارات تفوق المنافسين.
القيادات الأكاديمية إجرائياً: هم أعضاء هيئة التدريس بجامعة المجمعة والذين

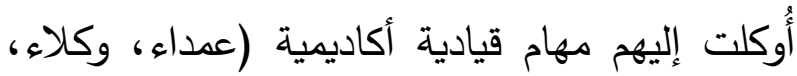
رؤساء أقسام، منسقات أقسام) بالجامعة.

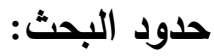
الموضوعية: التعرف على أبرز المتطلبات البشرية

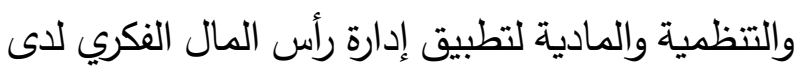
طلبة جامعة المجمعة من وجهة نظر القيادات الأكاديمية. - الانه المكانية: جامعة المجمعة. الزمانية: الفصل الدراسي الثاني من العام الجامعي 1441-1440هـ البشرية: القيادات الأكاديمية في جامعة المجمعة (عمداء، وكلاء، رؤساء أقسام، منسقات أقسام).

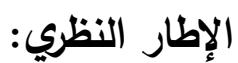
أولا: إدارة رأس المال الفكري في المؤسسات

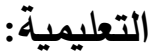
مفهوم إدارة رأس المال الفكري: يعتبر مفهوم رأس المال الفكري من المفاهيم التي حظيت باهتمام واسع مطلع القرن الحالي، وذلك لكونه

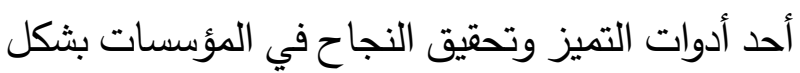
عام والمؤسسات التعليمية بشكل خاص، وقصد برأس المال الفكري أنه "مجموعة من الأشخاص الذين يمتلكون المعارف والخبرات والمنجزات التي تمكنهم من الإسهام في أداء المنظمات التي يعملون بها" لهربات (الزهيري،2012م) 
- تسعى إدارة رأس المال الفكري بالقرن الحادي تنظيمية تتميز بالمرونة والثفافية والقدرة على تعزيز والعشرين إلى زيادة إنتاجية العمل المعرفي والفرد العلاقات الإيجابية. رابعاً: نظم فعالة لرفع كفايات الموارد البشرية: كي البهة

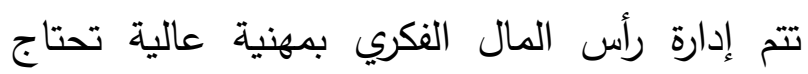

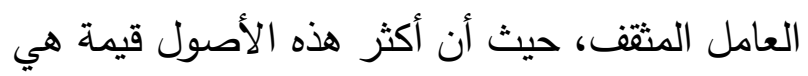
الأصول الفكرية. المعارف والمهارات المتوافرة لدى الأفراد إلى نظم فاعلة

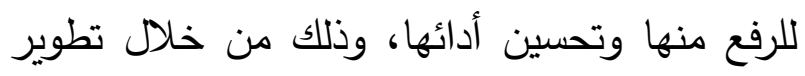

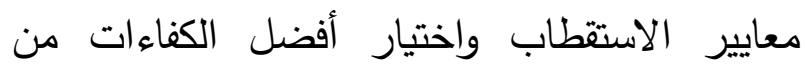
العاملين، وإتاحة فرص التطوير المهني والتعليم المستمر للعاملين، وتحفيزهم على تطوير ممارساتهم

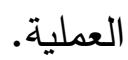

ويمكن تكوين رأس المال الفكري داخل الجامعة من خلال العناصر التالية: (عبدالسلام وعلة، 2011م) - - مناعة رأس المال الفكري

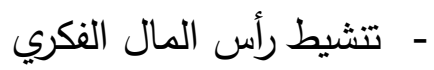

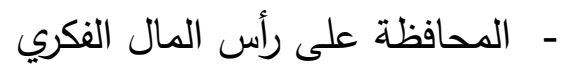
- الاهتمام بالمستفيدين تتمثل مبادئ إدارة رأس المال الفكري في النقاط النقاط التالية: (غبور،2015م) - الاستفادة القصوى من رأس المال الفكري الموجود

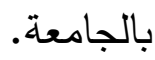
- هيكلة رأس المال الفكري بحفظ المعلومات داخل

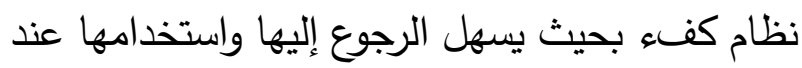

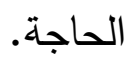
- توفير الموارد التي تحتاجها الجامعة لبناء شبكة داخلية لإدارة رأس المال الفكري بها. - زيادة العمليات التي تساعد على اكتثاف وتدعيم تدفق القدرات المعرفية والتتظيمية للأفراد. - ميزة تنافسية تميزها عن غيرها لتفادي المنافسة الثديدة، ومن تعظيم نقاط قوتها. أبعاد إدارة رأس المال الفكري: تتحدد أبعاد إدارة رأس المال الفكري في الجامعة الفال بالأبعاد الأربعة التالية: (العصفور،2012م)؛

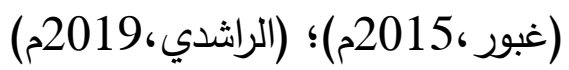
أولاً: سياسات عمل تنافسية: تتمثل في قدرة الجامعة على صياغة وتطبيق استراتيجيات وإجراءات العمل التي تجعلها تتميز في أدائها وأنشطتها عن غيرها من

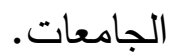
ثانياً: الثقافة التنظيمية الداعمة: وتتوفر من خلال امتلاك الجامعة لرؤية استراتيجية محفزة على الإبداع

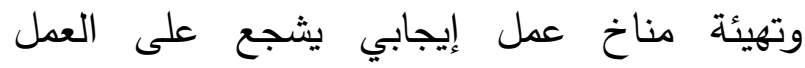
الجماعي، مع امتلالك جميع العاملين لرؤية مشتركة حول المهام التي يؤدونها، والتحسين المستمر للأداء فيها. ثالثًا: البيئة التظيمية المناسبة: وهي جميع العوامل الداخلية والخارجية التي تؤثر على الجامعات فتؤثر بها وتتأثر بها وتتفاعل معها في ظل تصميمات 
- - تعزيز الثقة بين أعضاء المجتمع الجامعي، وتتمية

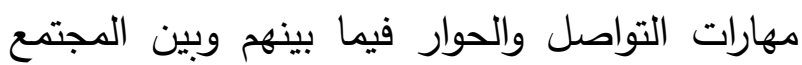
المحيط لأن ذلك يعزز من التماسك والولاء والمواطنة للجامعة التي يعملون بها. ثانياً: متطلبات إدارة رأس المال التنظيمي والمادي: يعد رأس المال التتظيمي الداعم الرئيس للموارد البشرية

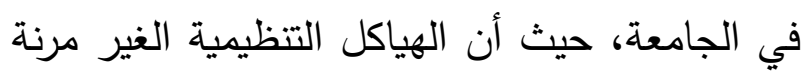
قد تجعل الأداء غير جيد ومستحيلًا، مهما بلغت درجة الئه كفاءة وإخلاص العاملين، وهناك العديد من المتطلبات

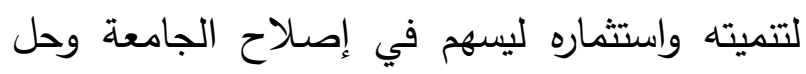
المشكلات التي تواجهها ومنها: - - بناء الهياكل الجامعية القائمة على فرق العمل بما يحول القرارات من الفردية للجماعية من خلال إشراكهر في اتخاذ القرارات وحل المشكلات التي تواجههم. - تهيئة البنية التحتية المتكاملة التجهيزات والإمكانات من معامل وتجهيزات تطلق العنان للمبدعين والمفكرين، لنشر أفكارهم وإبداعاتهم ومن ثم يكون مردودها إيجابيًا على الجامعة. - إتاحة الوقت الكافي للعاملين بالجامعة للانخراط في التعلم الفردي والجماعي من خلال اللقاءات والزيارات التبادلية بين العاملين لنقل المعارف والخبرات فيما

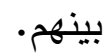
- إيجاد ثقافة جامعية تعاونية تعزز عمليات التعلم وتبادل الخبرات لديمومة التعليم واستمراره داخل
- المحافظة على رأس المال الفكري في الجامعة

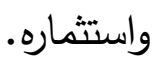
متطلبات إدارة رأس المال الفكري: لتطبيق إدارة رأس المال الفكري بالجامعات فإن ذلك الك يتطلب متطلبات بشرية، وتتظيمية ومادية، وعلاقات توجزها الباحثة فيما يلي:

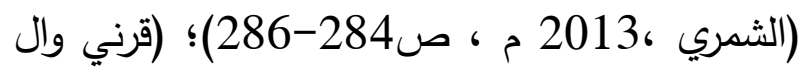
عتيقي،2012م،ص297-307)؛

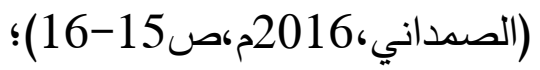

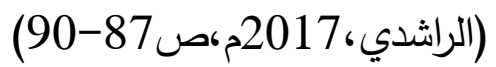
أولاً: متطلبات إدارة رأس المال البشري: يعد رأس المال البشري من أهم الموارد التي تمتلكها

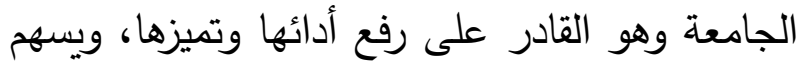
في تطوير وتحسين كافة جوانبها، ولاستثماره وتتميته فإن ذلك يتطلب: - تشجيع العاملين وتحفيزهم وتتمية مهاراتهم ومعارفهج من خلال الإلتحاق ببرامج التتمية المهنية واللقاءات والورش التدريبية التي تسهم في إكسابهم المزيد من الخبرات التي تمكنهم من حل المشكلات واتخاذ القرارات داخل الجامعة، ومن ثم تولد لديهم

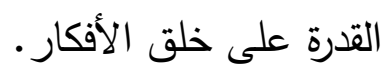
- تتمية العمل الجماعي بين العاملين والعمل كفريق العقد

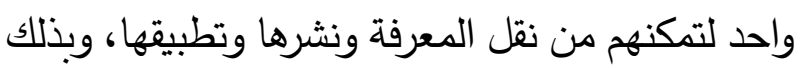
تسهم في تبادل الخبرات وتشاطرها فيما بينهم في ظل بيئة تتظيمية ملائمة. 
خلال عقد البرامج المهنية التي تتوائم والاحتياجات التدريبية للعاملين في الجامعة. - تشجيع العاملين للمشاركة في ل اللقاءات والاجتماعات بين الجامعات وذلك لنقل الخبرات والمعارف فيما بينهم ومن ثم تطبيقها في ممارساتهح

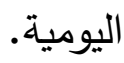
- تعزيز الثقة المتبادلة بين جميع منسوبي الجامعة من خلال الثفافية والتعاون وتحقيق مبدأ المساواة بين الجميع لزيادة الوحدة والتماسك والولاء والانتماء بين

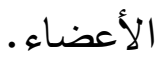
- بناء نظام للمكافآت والحوافز التي تثجع على بناء العلاقات وتقويتها، بحيث تكون هذه المكافآت جماعية وليست فردية لتعزز العمل الجماعي التعاوني ومن ثم تعزيز تماسك منسوبي الجامعة وترابطهم.

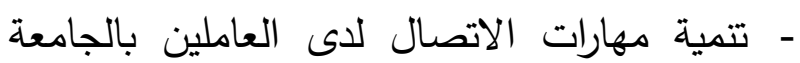
والعمل على بناء العلاقات وبناء شبكات العمل ليتمكن العاملون من تثاطر المعرفة مع زملائهم. - تعزيز العلاقة من المجتمع الخارجي من خلال التواصل المباشر والحوار واستمثار المجالس التي تعقد داخل الجامعة للاستفادة مما يقدمونه من أفكار تجارب يكون مردودها إيجابي على الجامعة.

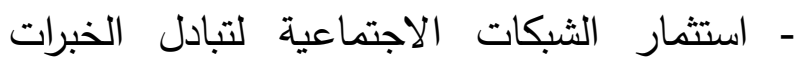
والتجارب بين العاملين بالجامعة.

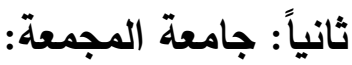
النثأة: تعد جامعة المجمعة من أحدث الجامعات السعودية والتي انضمت لمنظومة الصروح العلمية
- توفير قواعد للمعلومات في الجامعة فذلك يسهم في حفظ المعلومات والبيانات المتعلقة بكل منسوبي الجامعة، ومن ثم يسهل الرجوع إليها عند الحاجة.

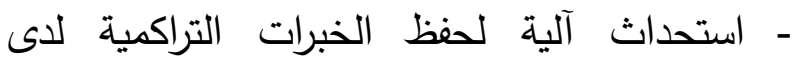
العاملين المتوقع تركهم للعمل بسبب النقل أو التقاعد. - توفير وسائل متعددة لسهولة انتقال المعلومات والمعرفة بين المستويات الإدارية المختلفة. - توسيع مساهمة المجتمع الخارجي والمحلي في الزدي صنع واتخاذ القرارات الجامعية من خلال عقد المجالس وإشراكهم في الجوانب المتعلقة بقضايا الجامعة والاستفادة من آرائهج تجاهها. - التقييم التظظيمي وتوجيه أنشطة الجامعة لضمان أولولية استراتيجية تنظيم إدارة رأس المال الفكري. - وجود آلية واضحة لدعم وتطوير أبحاث واتبتكارات العاملين بالجامعة وحفظها ونشرها. ثالثاً: متطلبات إدارة رأس مال العلاقات : تعد العلاقات من الجوانب الهامة لاستمرارية الموارد

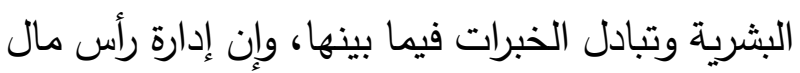
العلاقات بالجامعة تتطلب: - - بناء العلاقات الإيجابية والبناءة سواء بين العاملين أنفسهم داخل الجامعة أو محيطها الخارجي لاستثمار تلك العلاقة في نقل الخبرات بين العاملين والاستفادة

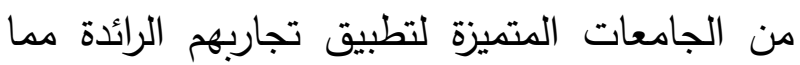
ينعكس إيجابًا على الجامعة.

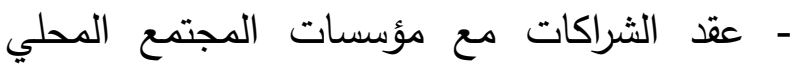

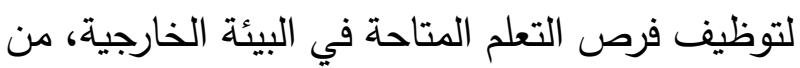


الكثيرة والكبيرة لتصبح رافدًا من روافد التعليم الجامعي خلال تقديم دورات متقدمة واستشارات في التخصصات المتوفرة في الجامعة. من خلال البحث وصرح ينتظر منه أبناء محافظة المجمعة والمحافظات رونات روات العلمي والبرامج والدراسات التي تتوافق مع ما رسم لهذه الجامعة من رؤية مستقبليه لتحقق رسالتها السامية

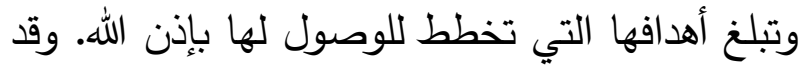
توجت مراحل تأسيس هذه الجامعة بصدور أمر ملكي

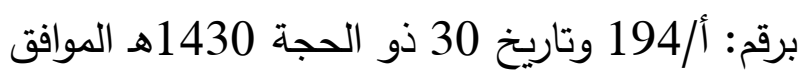
17 ديسمبر 2009م بتعيين الدكتور خالد بن سعد بن محمد المقرن مديراً لجامعة المجمعة بالمرتبة الممتازة. ليبدأ العمل في هذه الجامعة بشكل أوسع وتتسارع الخطوات لتطوير الكليات القائمة ومواصلة إنثاء كليات جديدة والموافقة على إضافة أقسام وتخصصات يحتاجها سوق العمل لتسير هذه الجامعة في ركب التطور والرقي بنظره تفاؤل لمستقبل مشرق لهذه الجامعة الناشئة لتكون منارة علميه متقدمة يشار إليها بالبنان تقف بين مثيلاتها من الجامعات الأخرى بكل

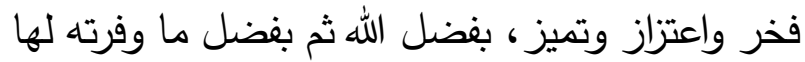
حكومة خادم الحرمين الثريفين من دعم ومساندة من خلال ما تم اعتماده للجامعة من ميزانية كبيرة.

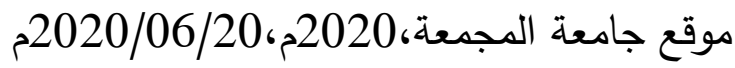
https://www.mu.edu.sa/ar/content/\%D8\%A7\% D9\%84\%D8\%AA\%D8\%A7\%D8\%B1\%D9\% $\underline{8 \mathrm{~A} \% \mathrm{D} 8 \% \mathrm{AE}}$ الرؤية: (الخطة الاستراتيجية الثالثة لجامعة

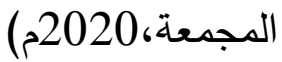
أن تكون جامعة المجمعة متميزة محليًا، منافسة عالميًا، مساهمة بكفاءة معرفيًا وتتمويًا ضمن نطاق الجامعة الكثير لتقدمه لهم. وجاء إنشاء هذه الجامعة بناء على موافقة خادم الحرمين الثريفين الملك عبدالله بن عبدالعزيز آل سعود كرحمه اللهرئيس مجلس الوزراء رئيس مجلس التعليم العالي، وذلك بتاريخ 3 رمضان 24 أغسطس ودل2009 م مع ثلاث جامعات أخرى في كل من مدينة الدمام ومحافظة الخرج ومحافظة شقراء، وبموجب هذا القرار تم ضم تسع كليات قائمه مع ثلاث كليات تحت الإنشاء لجامعة المجمعة، تثمل عددًا من المحافظات والمراكز وهي المجمعة، الزلفي، الاءل الغاط، رماح، حوطة سدير حيث تقدم هذه الجامعة خدمتها لمنطقة جغرافيه كبيرة تشمل عدة محافظات ومدن وهجر اكتمل فيها انتشار التعليم العام لتكمل هذه الجامعة منظومة التعليم فيها وتحقق هدف وزارة التعليم بالتوسع في التعليم الجامعي ليشمل كل أرجاء

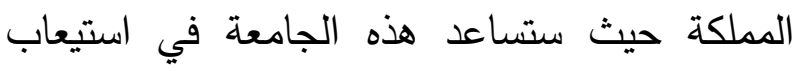
الأعداد المتزايدة من خريجي الثانوية العامة وتحدث استقرار اجتماعي ونفسي لأبناء وبنات المنطقة والتخفيف على الجامعات في المدن الكبيرة إضافة للحراك العلمي والثقافي الذي ستضيفه هذه الجامعة للمجتمع المحلي. مع العمل على خدمة المجتمع بشكل واسع في عدة مجالات اجتماعية وتوعوية وتثقيفية وتدريبه مع أمكانية الارتقاء بمستوى الأداء الوظيفي

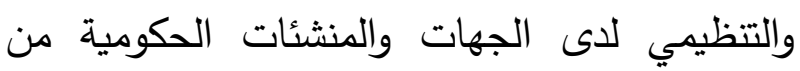


الرسالة: (الخطة الاستراتيجية الثالثة لجامعة وكيلة الكلية من بين عضوات هيئة التدريس السعوديات المتميزات بالكفاءات العلمية والإدارية بقرار

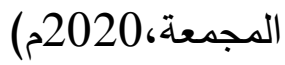

من معالي مدير الجامعة بناءً على ترشيح من عميد

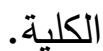

وكيل الكلية للثؤون التعليمية: وكيل الكلية للشئون التعليمية هو عضو هيئة التدريس بالكلية المكلف بالإشراف على سير العملية التعليمية في مرحلة الدراسة الجامعية، وتتفيذ السياسات والبرامج المعتمدة في مجال الخدمات التعليمية. وكيل الكلية لثؤون الطلاب: وكيل الكلية لشئون الطلاب هو عضو هيئة التدريس بالكلية المكلف بالإثراف على تتفيذ السياسات والبرامج المعتمدة في كافة مجالات شئون الطلاب وتحقيق

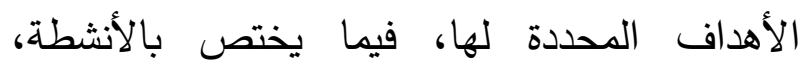
والخدمات الطلابية، والارشاد الأكاديمي بالكلية، بالتنسيق مع عميد الكلية. وكيل الكلية للتطوير والجودة: وكيل الكلية للتطوير والجودة هو عضو هيئة التدريس بالكلية المكلف بالإثراف على عمليات التطوير والجودة، وتحقيق معايير الاعتماد والتقويم الأكاديمي

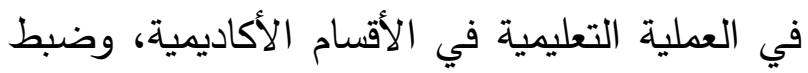
جودة العمل الإداري داخل الكلية والعمل على تطوير وتحسين الأداء في كافة الجوانب ونشر ثقافة الجودة. ولكل منهم اختصاصاته ومهامه وصلاحياته الخاصة
الالتزام بتوفير تعليم تتافسي، وإنتاج معرفي نوعي،

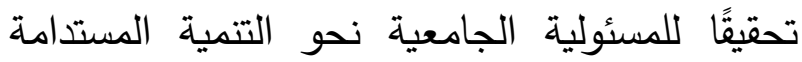

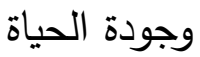

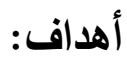
الأهداف الاستراتيجية للجامعة: (الخطة الاستراتيجية الثالثة لجامعة المجمعة،2020م) 1. الالتزام بالحوكمة الثاملة. 2. الارتقاء بمكانة الجامعة. 3.تحقيق التنافسية في مخرجات البرامج التعليمية 4. تعزيز إنتاج المعرفة 5. تحسين جودة الخدمات القيادات الأكاديمية بجامعة المجمعة: عميد الكلية: استناداً للمادة رقم ( 37) من نظام مجلس التعليم العالي والجامعات فإن عميد الكلية هو: عضو هيئة تدريس يتولى إدارة الثؤون العلمية والإدارية والمالية للكلية في حدود النظام ولوائحه، ويتولى تمثيل الكلية أمام الجهات المختلفة داخل وخارج الجامعة. وكيلة الكلية لأقسام الطالبات: هي عضوة هيئة التدريس المكلفة بالإشراف على العملية التعليمية والأكاديمية والبحثية والإدارية والمالية، والمسؤولة عن تتظيم العمل في الكلية في أقسام الطالبات وتسيير شؤونها بما تقتضيه مصلحة العمل وفق لوائح وأنظمة مجلس التعليم العالي. وتعين 
علاقة لإدارة رأس المال الفكري بتحقيق الميزة التتافسية في الجامعات، وقد أوصلت باستقطاب الكفاءات المتميزة والحفاظ عليها من التسرب. وهدفت دراسة (قثقش،2014م) إلى معرفة العلاقة بين الإجراءات الإدارية التي تتبعها الجامعات في إدارة رأس المال الفكري وتعزيز الميزة التتافسية لديها، والإجابة عن مدى تأثير كل مكون من مكونات رأس المسريز المال الفكري في تعزيز الميزة التتافسية لاى الجامعات

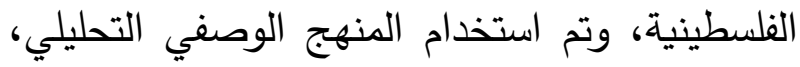
وشملت عينة الدراسة الهيئة الإدارية العليا وهم (رئيس قسم، مساعد مدير دائرة، مدير دائرة، مساعد عميد، مساعد رئيس جامعة، مستثار رئيس جامعة، نائب رئيس جامعة)، والبالغ عددهم 365 موظفًا في منصب إداري بالجامعات المستهدفة، وقد نتجت الدراسة إلى وجود موافقة كبيرة من العاملين في الجامعات الفلسطينية في قطاع غزة على رأس المال الفكري، وجود علاقة ذات دلالة إحصائية بين إدارة رأس المال علمال الفكري وتحقيق الميزة التنافسية في الجامعات الفلسطينية بقطاع غزة، هناك تفاوت في علاقة كل مكون من مكونات رأس المال الفكري في تعزيز الميزة التنافسية لدى الجامعات الفلسطينية، هناك علاقة لككان العمل والمسمى الوظيفي على الإجراءات الإدارية المتبعة في تحقيق الميزة التتافسية، وقد أوصت إلى ضرورة الاهتمام بالكادر البشري، وضرورة

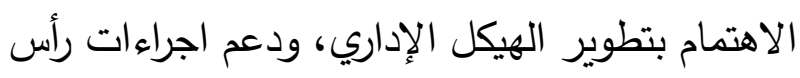
مال العلاقات في الجامعات.

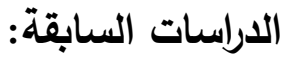
تتوعت الدراسات التي تتاولت موضوع رأس المال الفكري وإدارته، فمنها دراسات محلية وعربية وأجنبية، فقد هدفت دراسة (الخضري،2015م) إلى التعرف على واقع إدارة رأس المال الفكري بالجامعات الفلسطينية، وذلك من خلال التعرف على مدى توافر مكونات رأس المال الفكري، حيث تكون مجتمع الدراسة من جميع الموظفين الإداريين والأكاديميين

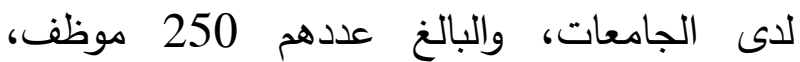
واستخدمت الدراسة المنهج الوصفي التحليلي، ونتجت إلى أن استجابة أفراد عينة الدراسة كانت بدرجة كبيرة، وقد أوصت بضرورة تثجيع إدارة الجامعة لموظفيها وطلابها على البحث العلمي، وضرورة بناء قدرات الموظفين من خلال التدريب والتطوير المتواصل. أما دراسة (آل سعيدي،2017م) فقد هدفت إلى التعرف على ممارسات إدارة رأس المال الفكري بمكوناته الثلاثة (رأس المال البشري، ورأس المال

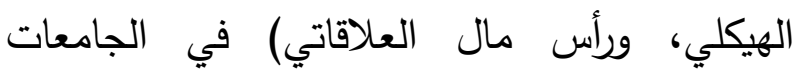
السعودية، بالإضافة لممارسات أبعاد الميزة التنافسية، وتوضيح العلاقة بين إدارة رأس المال بتحقيق الميزة التنافسية للجامعات السعودية، وقد استخدمت المنهج الوصفي الارتباطي، والاستبانة كأداة للدراسة حيث تكونت عينة الدراسة من 1937 عضو هيئة تدريس ولاطي وقيادات أكاديمية، وأظهرت العديد من النتائج منها:

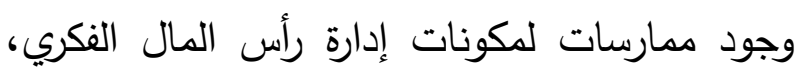

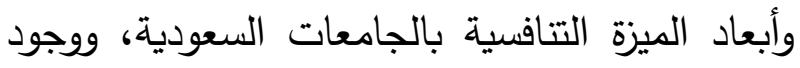


مديرًا، واستخدمت الاستبانة كأداة لجمع البيانات،

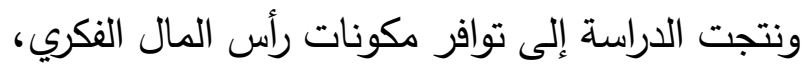
ومعايير جودة الأداء المؤسسي في البرنامج بدرجة كبيرة، ومن أهم التوصيات التعامل مع رأس المال الفكري على أنه مورد رئيسي واستراتيجي من بين الموارد التي يمتلكها البرنامج، ومراقبته من خلال

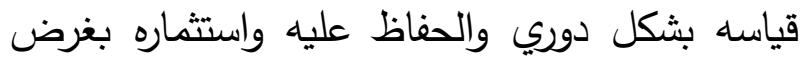
التطوير المستمر ، وبناء ثقافة تنظيمية إيجابية حول رأس المال الفكري وأهميته، ونشرها وتعزيزها لما يمثله من قيمة للبرنامج على المستوى المحلي.

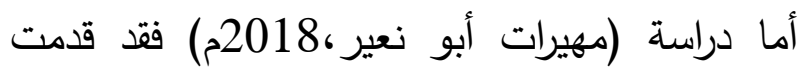
تصور مقترح لتطوير التعليم الجامعي وفقًا لرأس المال الفكري، وقد تم تطوير أداة تكونت من أربعة متطلبات، وبلغت عينة الدراسة من (500) عضو من أعضاء هيئة التدريس في الجامعات الأردنية الرسمية، وأظهرت النتائج أن واقع رأس المال الفكري في تطوير التعليم الجامعي من وجهة نظر العينة كانت بدرجة مرتفعة، حيث جاء مجال المتطلبات المعرفية بالمرتبة الأولى، والمتطلبات الفنية في المرتبة الأخيرة. وجاءت دراسة (القرشي، 2011م) تحلل أهم الاتجاهات العالمية المعاصرة ذات العلاقة بتتمية رأس المال الفكري في التعليم الجامعي، وتحديد أهم أبعاد تتمية رأس المال الفكري بالتعليم الجامعي المعاصر ، وابراز أهم متطلبات تتمية رأس المال الفكري بالجامعات السعودية، وقد استخدمت المنهج الوصفي التحليلي من لهن

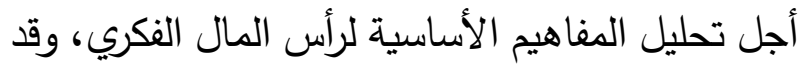

أما دراسة (2014 Ramirez \& Gordillo) فقد هدفت إلى تقديم نموذج لغرض التعرف على رأس المال الفكري وتقديره في الجامعات الإسبانية، من خلال تقديم مجموعة من مؤشرات المال الفكري لمساعدة الجامعات عن طريق تقديم معلومات مفيدة إلى حملة أسهمها بما يساهم في تحقيق قدر أكبر من الثفافية والمساءلة والقابلية للمقارنة في قطاع التعليم

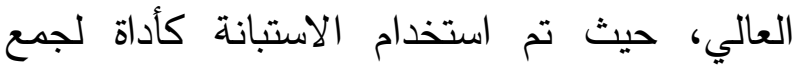
البيانات، وتكونت عينة الدراسة من أعضاء الدجالس الاجتماعية في الجامعات الاسبانية العامة بهدف التعرف على العناصر غير الملموسة التي يطلبها حملة الأسهم أكثر من أي شيء آخر، وتوصلت إلى الى النتائج التالية: تحديد العناصر غير التير الملئوسة التي تحتاج إلى قياس، والتي تشكلت نتائج الدراسة التجريبية منها، التعرف على مجموعة متجانسة من المؤشرات أن المؤلفات العلمية والمهنية قدمت العديد من المقترحات لقياس رأس المال الفكري، وأوصت المؤست بضرورة البحث عن نماذج لقياس رأس المال الفكري لأن عدد النماذج المعتمدة على قياس رأس المال الفكري في الجامعات قليلة. وهدفت دراسة (عبدالهادي،2017م) إلى التعرف على رأس المال الفكري ودوره في جودة الأداء المؤسسي اعبدي في برنامج التربية والتعليم بوكالة الغوث وتثغيل اللاجئين في قطاع غزة، واعتمدت الدراسة على المنهج الوصفي التحليلي، وتم استخدام أسلوب الحصر الثامل على مجتمع الدراسة والبالغ عددهم 268 
الإدارة والخدمات، ممثلي منظمات الأعمال، وأعضاء هيئة التدري)، وقد نتجت إلى أن الجامعات الحكومية الأسبانية بحاجة إلى نشر معلومات عن رأس المال الفكري بهدف جعل نظام الجامعة القائم أكثر ملائمة

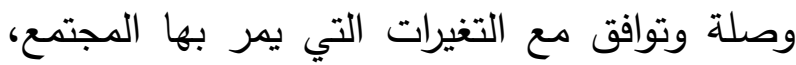
وأنها تسعى إلى إجراء تغييرات عميقة وكبيرة لتحسين الفعالية والكفاءة، والثفافية للمعلومات لما لها من دور هام في إدارة رأس المال الفكري. وهدفت دراسة (القبلي،2015م) إلى التعرف على إلى درجة ممارسة قيادات كليات التعليم العالي الأهلي بمدينة الرياض لمتطلبات رأس المال الفكري المتمثل

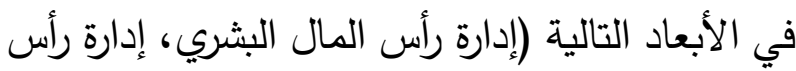
المال التنظيمي، إدارة رأس مال المستفيدين)، واعتمدت الدراسة المنهج الوصفي المسحي، واستخدمت الاستبانة كأداة لجمع البيانات طبقت على عينة من لن (100) عضو هيئة تدريس بست كليات أهلية بالرياض، وقد نتجت إلى أن ممارسة إدارة رأس المال البشريء والتنظيمي جاء بدرجة متوسطة، أما إدارة رأس مال المستفيدين فقد جاء بدرجة عالية، وأوصت بضرورة مراعاة الرغبات والقدرات للعناصر البشرية

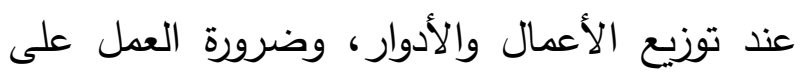
توفير الأمان الوظيفي لدى العناصر البشرية. وقد هدفت دراسة (القرني،2020م) إلى بناء استراتيجية مقترحة لإدارة رأس المال الفكري في دراسي الجامعات السعودية، في ضوء اقتصاد المعرفة، وقد استخدم المنهج الوصفي المسحي، والوصفي الوثائقي،
توصلت الدراسة إلى أن الجامعات السعودية تعاني من ضعف في توفير متطلبات تنمية رأس المال الفكري والانتقال إلى الاقتصاد المبني على المعرفة، وعليه فإن الجامعات السعودية مطالبة بالعمل على تطوير تقنيات وأساليب تجميع المعلومات بطريقة ذكية ورشيدة، والعمل على إيجاد ثقافة تعليمية متميزة تدعم

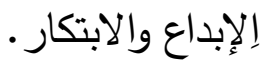
وهدفت دراسة (ويح،2013م) إلى التعرف على أراء أعضاء هيئة التدريس لمدى توافر متطلبات رأس المال الفكري بكوناته (البشري، الهيكلي، العلاقاتي، المعلوماتي) في جامعة بنها لتحقيق الميزة التنافسية

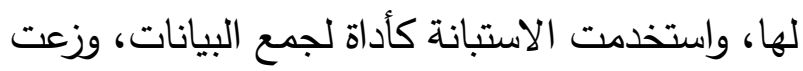
على عينة مكونة من (109) عضو هيئة تدري،، وقد نتجت الدراسة إلى توفر متطلبات تطوير رأس المال الفكري بجامعة بنها بدرجة متوسطة. أما دراسة كارلوس (coreoles، أوضحت مدى حاجة الجامعات الإسبانية لإدراج المعلومات عن رأس المال الفكر في نظم معلومات المحاسبة، وتقديم المساعدة للجامعات الحكومية الإسبانية لتطوير قدرتها على تحديد وقياس وإدارة أصولها غير الملموسة، وبيان أهمية رأس المال الفكري كأدوات لمواجهة التحديات الجديدة التي تواجه الجامعات الحكومية الإسبانية، واستخدمت الاستبانة

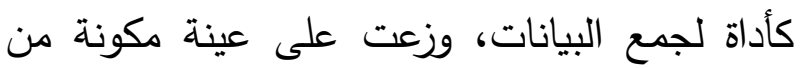
(247) من حكام الجامعة (نائب مستثار الأمين العام، الأمين العام للمجلس والمدير ، الطلاب، موظفي 
المال الفكري لاى طلاب وطالبات جامعة المجمعة

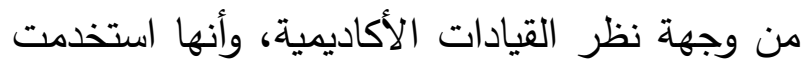
المنهج الوصفي المسحي.

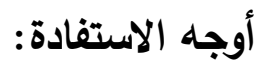
استفادت الدراسة الحالية من الدراسات السابقة في دعم مشكلة البحث، وبناء الإطار النظري وأداة الدراسة. الإجراءات المنهجية للبحث:

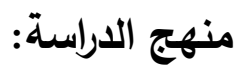
في ضوء طبيعة مشكلة الدراسة، وأسئلتها، وأهدافها استخدت الباحثة المنهج الوصفي المسحي للإجابة عن أسئلة الدراسة. مجتمع الاراسة: تكوّن مجتمع الدراسة من جميع القيادات الأكاديمية في جامعة المجمعة (عمداء، وكلاء، رؤساء أقسام،

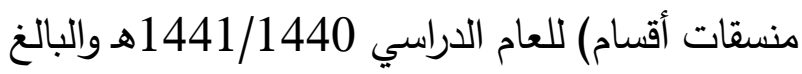
عددهم (73) قائد، وتتمثل الخصائص الثخصية والوظيفية لأفراد الدراسة في: الوظيفة والمرتبة الوظيفية وسنوات الخبرة، ذلك على النحو التالي:
ومسح الخبراء، والاستبانة كأداة للدراسة، تم تطبقها على 235 قائد أكاديمي في الجامعات السعودية، وقد توصلت الدراسة إلى أن درجة ممارسة إدارة رأس المال الفكري بالجامعات السعودية كبيرة، وموافقة أفراد عينة الدراسة على متطلبات ومعوقات إدارة رأس المال الفكري في الجامعات السعودية بدرجة كبيرة. التعقيب على الدراسات السابقة: في ضوء ما تم مناقثته في الدراسات السابقة يمكن استتتاج الملاحظات التالية:

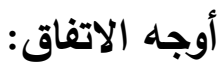
1. منهج الدراسة: اتفقت الدراسة الحالية مع دراسة (القبلي،2015م)، (القرني،2020م) في منهج الدراسة

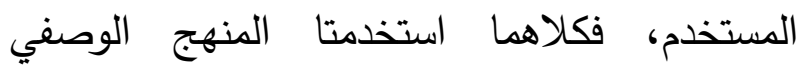

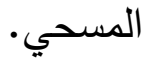
2. أدوات الدراسة: اتفقت الدراسة الحالية مع جميع الدراسات السابقة باستخدام الاستبانة كأداة لجمع لـع

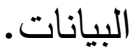

3. عينة الدراسة: تثابهت الدراسة الحالية مع دراسة (قثقش،2014م) في عينة الدراسة من حيث أنها

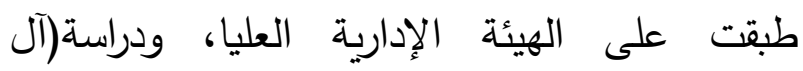
سعيدي،2017)؛ و (القرني،2010م) حيث أنها طبقت على القادة الأكاديميين والدراسة الحالية طبقت على

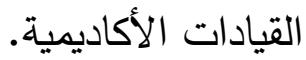
أوجه الاختلاف: تميزت الدراسة الحالية عن الدراسات السابقة أنها هدفت إلى التعرف على متطلبات تطبيق إدارة رأس 


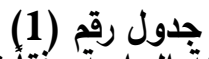

توزبع أفراد عينة الدراسة وفقاً لمتفير الوظيفة

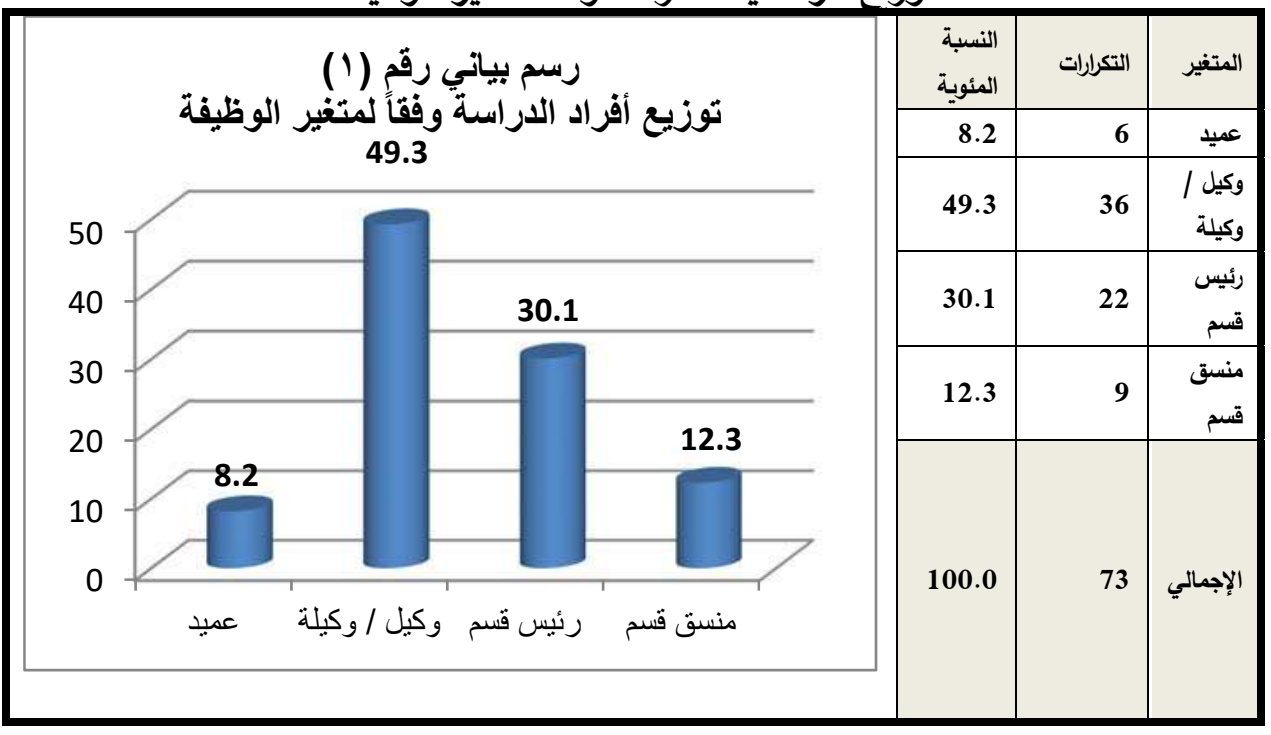

يوضح الجدول رقم (1) توزيع أفراد الدراسة وفقاً لمتغير الوظيفة، حيث أن هناك (49.3\%) من أفراد عينة الدراسة يشغلون وظيفة وكيل / وكيلة وهم الفئة الاكبر من عينة الدراسة، في حين أن هناك (30.1\%) من أفراد الدراسة يشغلون وظيفة رئيس قسم، وبينما (8.2\%) من أفراد الدراسة يشغلون وظيفة عميد وهي جميعها وظائف أكاديمية قيادية.

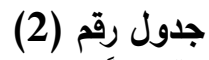

توزبع أفراد الدراسة وفقاً لمتغير المرتبة الوظيفة

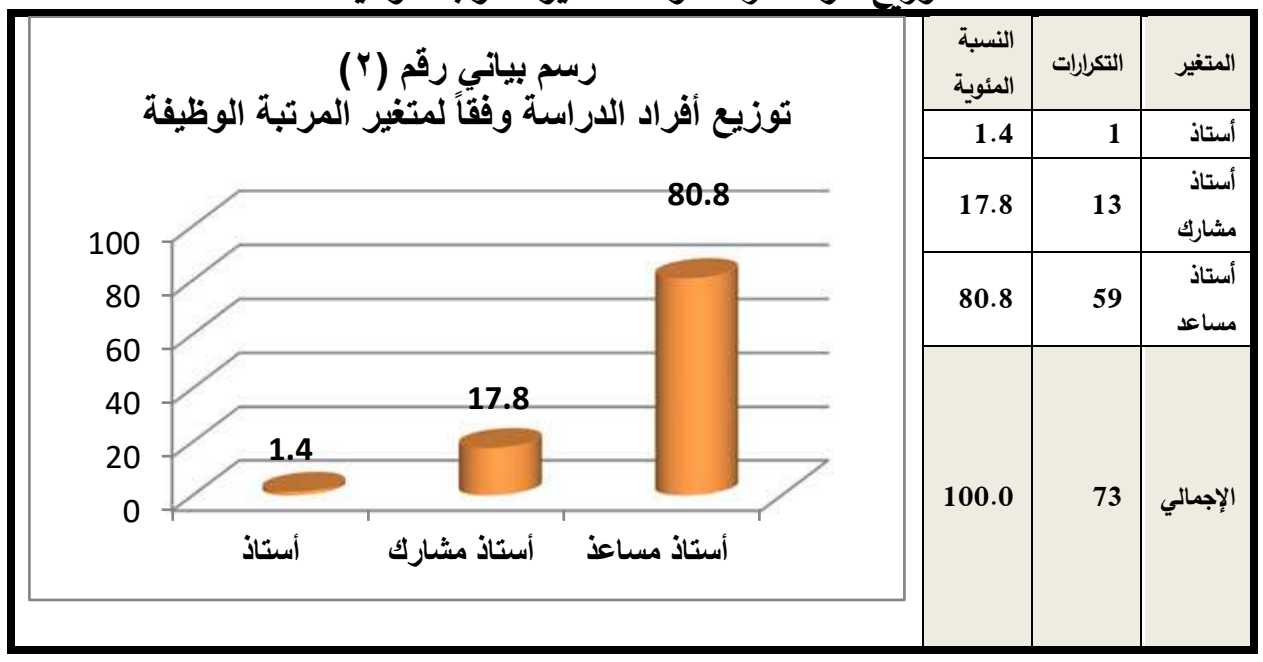

يوضح الجدول رقم (2) توزيع أفراد الدراسة وفقاً لمتغير المرتبة الوظيفة، حيث أن هناك (80.8\%) من أفراد عينة الدراسة مرتبتهح الوظيفية أستاذ مساعد وهم الفئة الاكبر من عينة الدراسة، و(17.8\%) من المبحوثين مرتبتهم الوظيفية أستاذ مشارك، وبينما (1.4\%) من أفراد العينة مرتبتهم الوظيفية أستاذ، وحيث أن جميعهم من قيادي الصف الأول بالجامعة والكليات. 
جدول رقم (3)

توزيع أفراد عينة الدراسة وفقاً لمتغير سنوات الخبرة

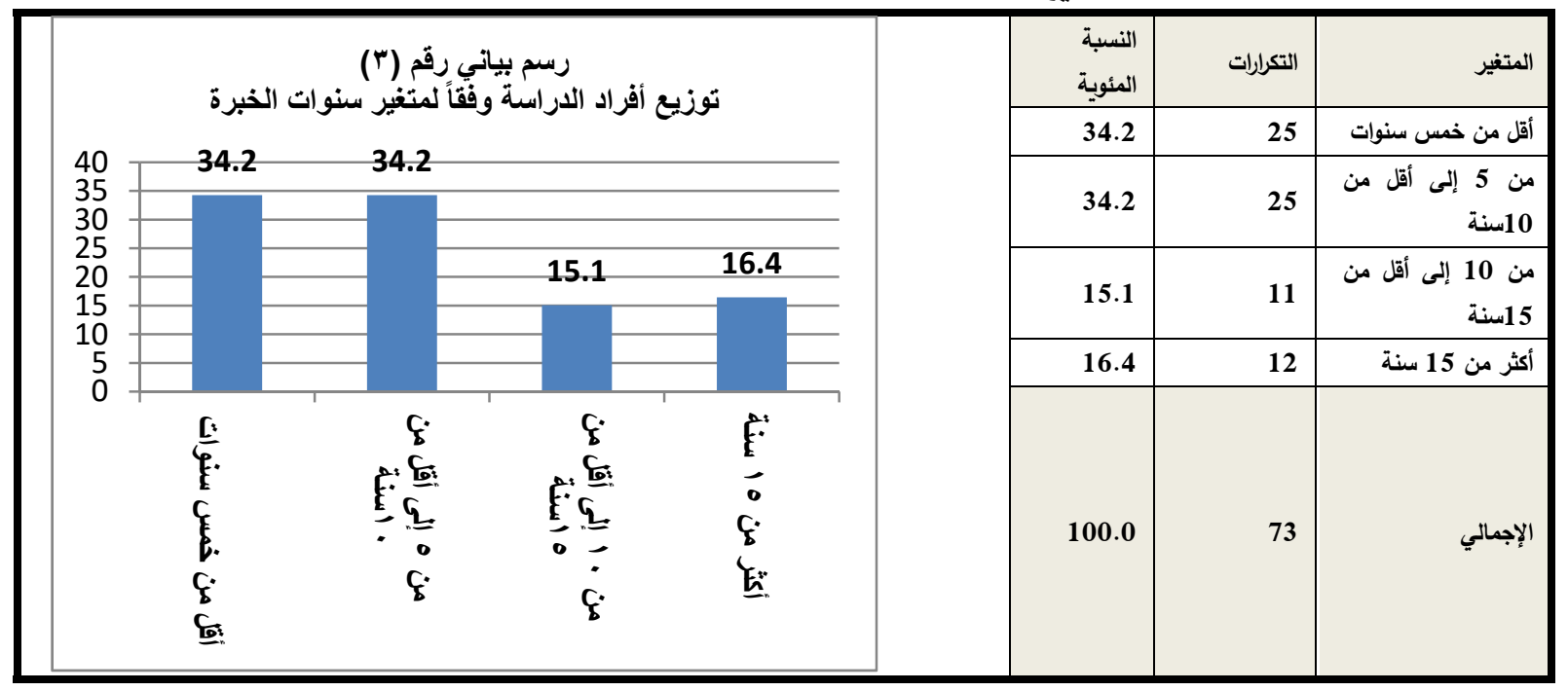

يتضح من خلال الجدول رقم (3) أن ما يزيد على ثلث أفراد عينة الدراسة (34.2\%) تتراوح سنوات خبرتهم (من 5 إلى أقل من 10سنة) ونسبة مساوية لها من المبحوثين سنوات خبرتهم أقل من خمسة سنوات وفي حين (16.4\%) من أفراد عينة الدراسة بلغت سنوات خبرتهم أكثر من 15 سنة وبينما (15.1\%) من أفراد العينة تتراوح سنوات خبرتهح (من 10 الى أقل من 15 سنة)، أي أن (65.8\%) من أفراد عينة الدراسة تتراوح سنوات خبرتهم من خمسة سنوات وأكثر في مجال العمل الأكاديمي. ل المحور الثاني: المتطلبات التنظيمية وتكون من أدوات الارراسة:

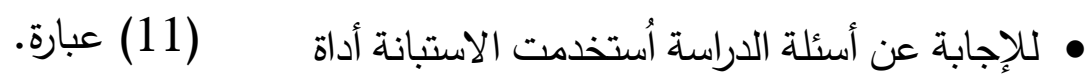
لجمع البيانات؛ حيث تكوّنت من قسمين رئيسين، المحور الثالث: المتطلبات المادية وتكون من (7) عبارات. وهما: وقد صمّمت الباحثة الاستبانة على أساس مقياس ليكرت الخماسي المُتدرّج؛ لقياس درجة استجابة أفراد عينة الدراسة للعبارات، الذي احتوى على البنود التالية:

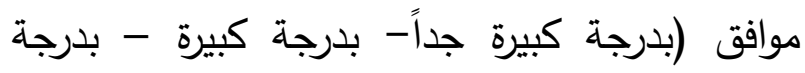

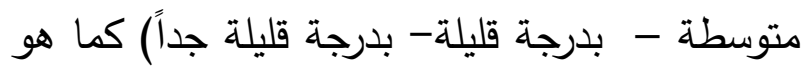
موضح في الجدول التالي: - القسم الأول: البيانات الأولية: (العمل الحالي، والرتبة العلمية، وسنوات الخبرة الوظيفية). - القسم الثاني: الذي تضمّن ثلاثتة محاور تتمثّل في متطلبات تطبيق رأس المال الفكري لدى طلبة جامعة المجمعة من وجهة نظر القيادات الأكاديمية، وهي كالآتي: ل المحور الأول: المتطلبات البشرية وتكون من (8) عبارات. 
جدول رقم (4): درجات مقياس ليكرت.

\begin{tabular}{|c|c|c|c|c|c|}
\hline موافق بدرجة قليلة جداً & موافق بدرجة قليلة & موافق بلرجة متوسطة & موافق بدرجة كبيرة & موافق بدرجة كبيرة جداً & درجة المُوافقة \\
\hline 1 & 2 & 3 & 4 & 5 & الارجة \\
\hline
\end{tabular}

العبارات حسب رؤيته؛؛ حتى أصبح عدد فقرات

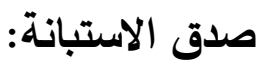
الاستبيان (26) عبارة. الصدق: أن تكون الأداة فعلًا قادرة على قياس ما صدق الاتساق الداخلي للأداة: بعد التأكد من الصدق ألأ الظاهري لأداة الدراسة قامت الباحثة بتطبيقهما ميدانياً

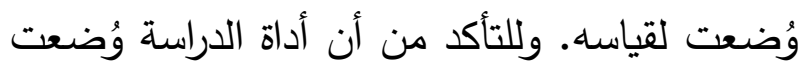

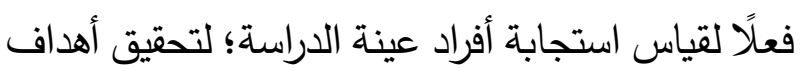

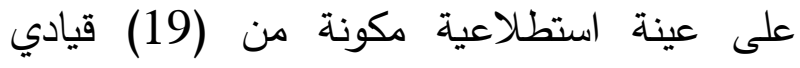
أكاديمية بجامعة المجمعة، تم اختيارهم عشوائياً من مجتمع الدراسة، ثم قامت الباحثة بحساب معامل لهابل

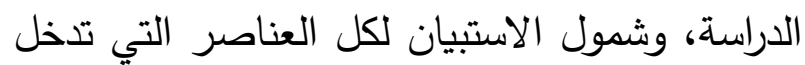

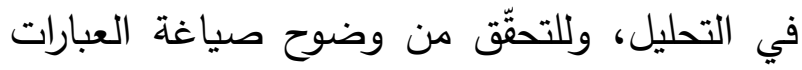
وشموليتها؛ اعتمدت الباحثة على نوعين من الصدق؛ الارتباط بيرسون لمعرفة الصدق الداخلي للاستبانة،

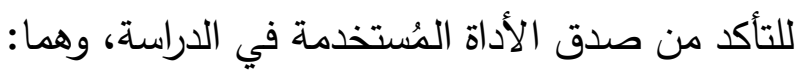
حيث تم حساب معامل الارتباط بين درجة كل عبارة الصدق الظاهري للأداة: أعدّت الباحثة الاستبانة في

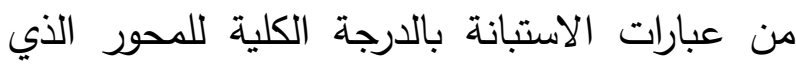

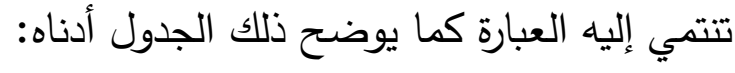

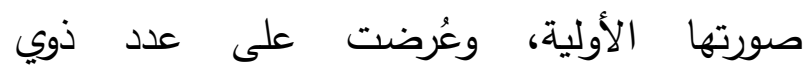
الاختصاص والخبراء، وتم حذف وإضافة بعض الإن جدول رقم (5): معامل الارتباط بين عبارات الاستبانة

\begin{tabular}{|c|c|c|c|c|c|c|c|c|}
\hline معامل ارتباط بيرسون & رقم العبارة & المحور & معامل ارتباط & رقم العبارة & المحور & معامل ارتباط & رقم العبارة & المحور \\
\hline$* * 0.648$ & 1 & \multirow{11}{*}{ 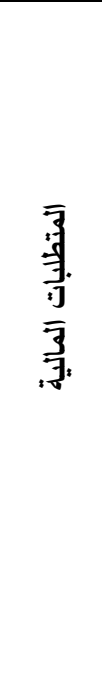 } & $* * 0.653$ & 1 & \multirow{11}{*}{ 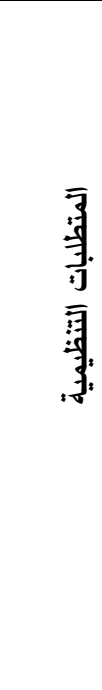 } & $* * 0.644$ & 1 & \multirow{11}{*}{ 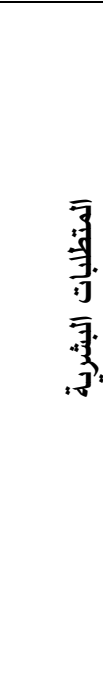 } \\
\hline$* * 0.676$ & 2 & & $* * 0.717$ & 2 & & $* * 0.702$ & 2 & \\
\hline$* 0.865$ & 3 & & *** 0.718 & 3 & & $* * 0.733$ & 3 & \\
\hline ** 0.804 & 4 & & **0.709 & 4 & & $* * 0.774$ & 4 & \\
\hline ** 0.649 & 5 & & * 0.773 & 5 & & *** 0.839 & 5 & \\
\hline ** 0.824 & 6 & & $* * 0.823$ & 6 & & $* 0.436$ & 6 & \\
\hline \multirow[t]{5}{*}{$* 0.815$} & 7 & & $* 0.587$ & 7 & & $* * 0.691$ & 7 & \\
\hline & & & **0.791 & 8 & & $* 0.567$ & 8 & \\
\hline & & & $* 0.554$ & 9 & & & & \\
\hline & & & $* * 0.882$ & 10 & & & & \\
\hline & & & $* * 0.879$ & 11 & & & & \\
\hline
\end{tabular}

"* * دال عذ مستوى الدلالة 0.01 فأقل " مال عند مستوى الدالة 0.05 فأقل 
تبيّن النتائج بالجدول (5)، أن قيم مُعَامل ارتباط كل ثبات الاستبانة:

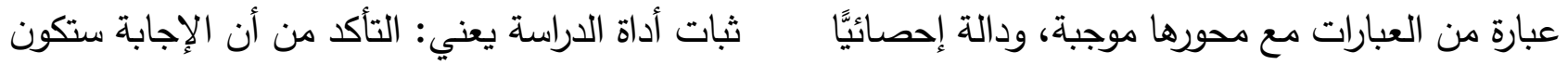

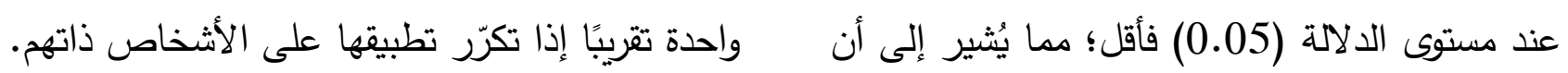

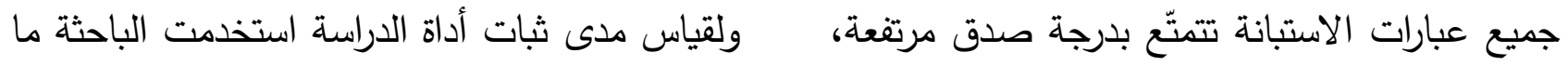
ويؤكد ذلك قوة الارتباط الداخلي بين جميع عبارات يلي:

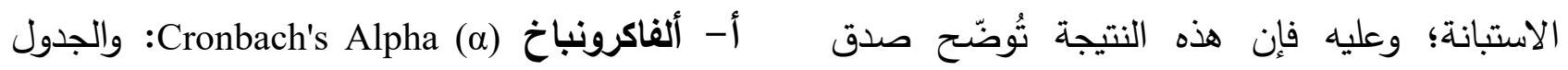
عبارات ومحاور الاستبانة وصلاحيتها للتطبيق التالي يوضّح ذلك.

جدول رقم (6) - جات

معامل ألفا كرونباخ لقياس ثبات أداة الاراسة

\begin{tabular}{|c|c|c|c|}
\hline الصدق & معامل ألفا كرونباخ (الثبات) & المحور & م \\
\hline 0.91 & 0.82 & المتطلبات البشرية & 1 \\
\hline 0.95 & 0.91 & المتطلبات التنظيمية & 2 \\
\hline 0.93 & 0.87 & المتطلبات المادية & 3 \\
\hline 0.97 & 0.94 & \multicolumn{2}{|c|}{ الثبات الكلي للاستبانة } \\
\hline
\end{tabular}

التطبيق الميداني للدراسة، وصلاحيتها لتحليل النتائج

والاجابة على أسئلة الدراسة واختبار فرضياتها.

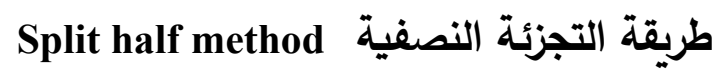
تم تقسيم مجالات الاستبانة إلى فقراتها الفردية

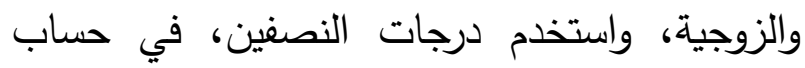
معامل الارتباط بينهما، ولحساب معامل ثبات درات الاستبيان تم استخدام معادلة سبيرمان براب براون Spearman Brown $\frac{1 / 2,2}{1 / 2,+1} \quad=\quad$ معامل الثبات
* الجذر التربيعي الموجب لمعامل ألفا كرونباخ توضح النتائج الموضحة في الجدول (6) أن قيمة ألفا كرونباخ كانت مرتفعة لكل مجال وتتراوح بين (0.82

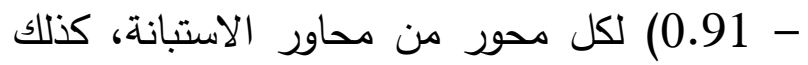
كانت قيمة معامل ألفا لجميع فقرات الاستبانة كانت (0.94)، وكذلك قيمة الصدق مرتفعة لكل مجال وتتراوح بين (0.91- 0.95) لكل محور من محاور

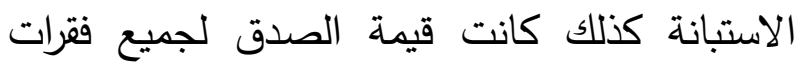
الاستبانة (0.97) وهذا يعني أن معاملي الثبات

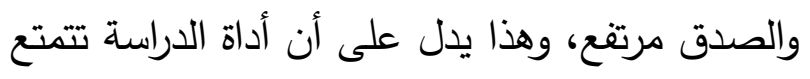
بدرجة عالية من الثبات يمكن الاعتماد عليها في لي 


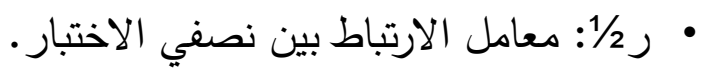

حيث:

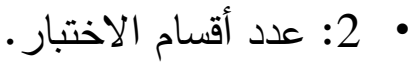

جدول رقم (7)

طريقة التجزئة النصفية لقياس ثبات الاستبانة.

\begin{tabular}{|c|c|c|c|}
\hline معامل الارتباط المعدل & معامل الارتباط & | المحور & b \\
\hline 0.82 & 0.69 & المتطلبات البشرية & 1 \\
\hline 0.95 & 0.90 & المتطلبات التنظيمية & 2 \\
\hline 0.86 & 0.75 & |المتطلبات المادية & 3 \\
\hline 0.94 & 0.89 & \multicolumn{2}{|c|}{ لثبات الكلي للاستبانة } \\
\hline
\end{tabular}

• الحصول على الموافقات الرسمية من الجهات

تخلص الباحثة إلى أن قيمة معامل الارتباط المعدل

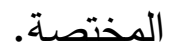
Spearman Brown وبلغ معامل الارتباط لجميع محاور أداة الدراسة المعدل توزيع أداة الدراسة.

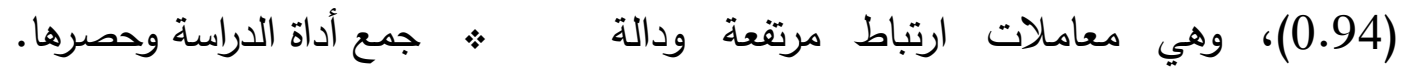

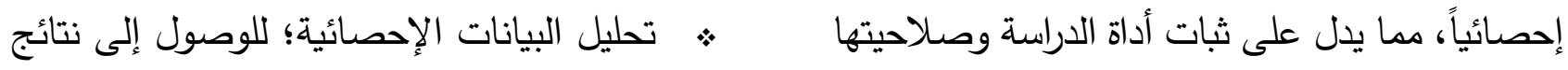

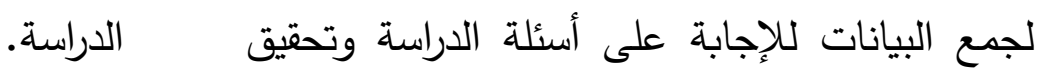
أساليب المعالجة الإحصائية للبيانات: بعد جمع البيانات من مجتمع الدراسة حُلّلت من خلال استخدام برنامج (SPSS)؛ حيث وزعت الدرجات على لئ حساب المدى للفئات كما يلي: أهدافها. إجراءات تطبيق الدراسة: طبقت الباحثة أداة الدراسة بعد الانتهاء من صياغتها بصورة نهائية على النحو التالي:

جدول رقم (8)

طول خلايا مقياس ليكرت

\begin{tabular}{|c|c|}
\hline طول الخلية & درجة الاستجابة \\
\hline من 1 إلى 1.79 & درجة قليلة جداً \\
\hline من 1.80 إلى 2.59 & درجة قليلة \\
\hline من 2.60 إلى 3.39 & درجة متوسطة \\
\hline من 3.40 إلى 4.19 & درجة كبيرة \\
\hline من 4.20 إلى 5.00 & درجة كبيرة جداً \\
\hline
\end{tabular}


مُعَامل ألفا كرونباخ (Cronbach's Alpha) - مُعَامل عرض نتائج الاراسة، ومناقشتها، وتفسيراتها: ارتباط بيرسون Pearson's Correlation Co- للإجابة عن اسئلة الدراسة تم حساب التكرارات، (efficient - طريقة التجزئة النصفية - التكرارات والنسب المئوية، والمتوسطات الحسابية، والانحرافات والنسب المئوية - المتوسط الحسابي - الانحراف المعيارية، والوزن النسبي، والترتيب؛ لمعرفة وجهة

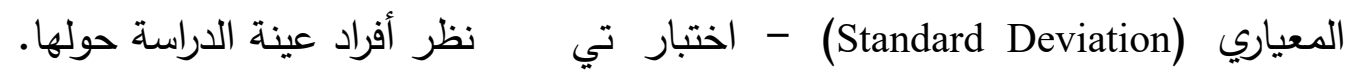
(Independent Sample t-test) التباين الأحادي (One Way ANOVA) (اختبار المال الفكري لدى طلبة جامعة المجمعة من وجهة نظر القيادات الأكاديمية؟ جاءت النتائج كما يُبيّنها

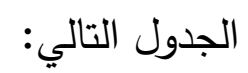

جدول رقم (9): وجهات نظر القيادات الأكاديمية حول المتطلبات البشربية لتطبيق إدارة رأس المال الفكري

لاى طلبة جامعة المجمعة

\begin{tabular}{|c|c|c|c|c|c|c|c|c|c|c|c|c|c|}
\hline 哥 & 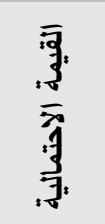 & $\begin{array}{l}\text { 易 } \\
\text { 可 }\end{array}$ & $\begin{array}{l}\overline{3} \\
.3 \\
\overline{3} \\
\text { j. }\end{array}$ & $\frac{\bar{x}}{\bar{x}}$ & $\begin{array}{l}\overline{3} \\
3 \\
3 \\
3\end{array}$ & 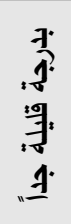 & $\begin{array}{l}\text { ج. } \\
\text { : } \\
\text { : }\end{array}$ & 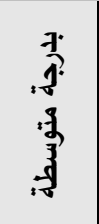 & 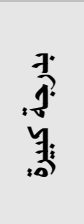 & 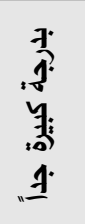 & & لاحصائية & م \\
\hline \multirow[b]{2}{*}{3} & \multirow[b]{2}{*}{0.001} & \multirow[b]{2}{*}{5.6} & \multirow[b]{2}{*}{73.6} & \multirow[b]{2}{*}{1.02} & \multirow[b]{2}{*}{3.68} & 3 & 5 & 21 & 28 & 16 & ك & \multirow{2}{*}{ 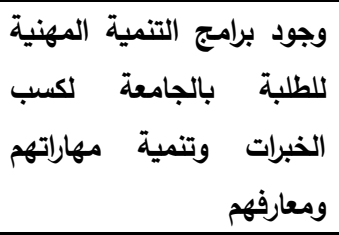 } & \multirow[t]{2}{*}{1} \\
\hline & & & & & & 4.1 & 6.8 & 28.8 & 38.4 & 21.9 & $\%$ & & \\
\hline \multirow[b]{2}{*}{1} & \multirow[b]{2}{*}{0.001} & \multirow[b]{2}{*}{4.6} & \multirow[b]{2}{*}{71.0} & \multirow[b]{2}{*}{1.03} & \multirow[b]{2}{*}{3.55} & 2 & 7 & 29 & 19 & 16 & 5 & \multirow{2}{*}{ 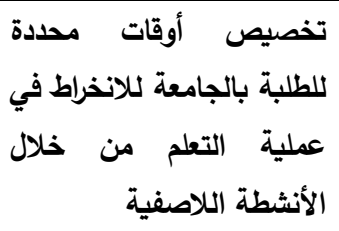 } & \multirow[t]{2}{*}{2} \\
\hline & & & & & & 2.7 & 9.6 & 39.7 & 26.0 & 21.9 & $\%$ & & \\
\hline \multirow[b]{2}{*}{2} & \multirow[b]{2}{*}{0.001} & \multirow[b]{2}{*}{5.6} & \multirow[b]{2}{*}{73.4} & \multirow[b]{2}{*}{1.03} & \multirow[b]{2}{*}{3.67} & 2 & 7 & 21 & 26 & 17 & ك5 & \multirow{2}{*}{ 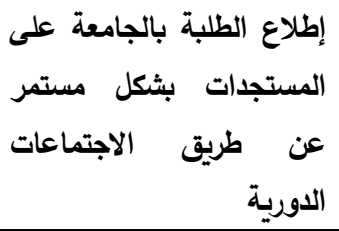 } & 3 \\
\hline & & & & & & 2.7 & 9.6 & 28.8 & 35.6 & 23.3 & $\%$ & & \\
\hline 8 & 0.001 & 12.0 & 82.2 & 0.79 & 4.11 & 0 & 2 & 13 & 33 & 25 & ك & & \\
\hline
\end{tabular}

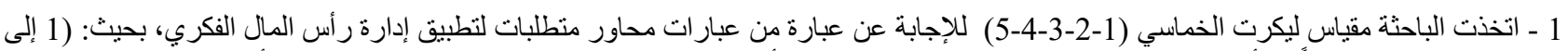

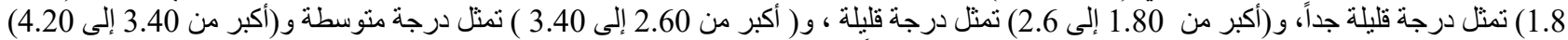
تمثل درجة كبيرة و(أكبر من 4.20 إلى من 5.00) تمثل درجة كبيرة جداً. 


\begin{tabular}{|l|l|l|l|l|l|l|l|l|l|l|lr|l|}
\hline & & & & & & & & & & & & & \\
\hline
\end{tabular}

المتوسط الحسابي دال إحصائياً عند مستوى دلالة 0.05 فأقل

يتضح من نتائج الجدول (9) أن المتطلبات البشرية لتطبيق إدارة رأس المال الفكري في جامعة المجمعة قد جاءت الفئ بدرجة كبيرة، حيث بلغ المتوسط الحسابي العام (3.85 من 5) وهو متوسط يقع في الفئة الثانية من فئات مقياس ليكرت الخماسي، كما أن الانحراف

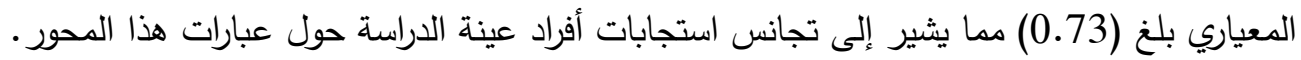
وتُقسر هذه النتيجة أهمية توافر المتطلبات البشرية لتطبيق إدارة رأس المال الفكري، لأن المكون البشري هو العنصر الأساسي في هي هي تطور ونجاح المنظمات لما له من أهمية بما يملكه من مهارات وخبرات ومعارف، وهو مورداً جوهرياً لا يمكن الاستغناء عنه، فهو مصدر التخطيط والابتكار والابداع. كما ويُلحظ في الجدول أعلاه موافقة أفراد عينة الدراسة على جميع المتطلبات البشرية بدرجة كبيرة ومتوسط حسابي يتراوح ما بين (4.11 إلى 3.55) من (5)، وقد بلغ الوزن النسبي لها ما بين (89.5\%) إلى (71,0\%) وهذا يتوافق مع دراسة (لخضري، 2015م)؛ (مهيرات وأبو نعير ،2018م) في ضرورة توافر المتطلبات البشرية لإدارة رأس المال الفكري بدرجة كبيرة. السؤال الثاني: ما المتطلبات التظيمية لتطبيق إدارة رأس المال الفكري لدى طلبة جامعة المجمعة من وجهة نظر القيادات الأكاديمية؟ جاءت النتائج كما يُبيّنها الجدول التالي: 
جدول رقم (10): وجهات نظر القيادات الأكاديمية حول المتطلبات التظيمية لتطبيق إدارة رأس المال

الفكري لاى طلبة جامعة المجمعة

\begin{tabular}{|c|c|c|c|c|c|c|c|c|c|c|c|c|c|}
\hline 雪: & 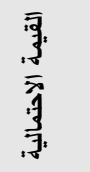 & 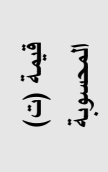 & $\begin{array}{l}\overline{3} \\
3 \\
\overline{7} \\
3.7\end{array}$ & $\overline{\frac{7}{7}}$ & 牙 & 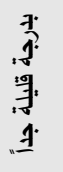 & ?ִ. & 每 & 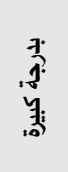 & 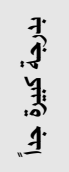 & & العبار & b \\
\hline \multirow{2}{*}{9} & \multirow[b]{2}{*}{0.001} & \multirow{2}{*}{7.6} & \multirow{2}{*}{77.0} & \multirow{2}{*}{0.95} & \multirow{2}{*}{3.85} & 1 & 5 & 18 & 29 & 20 & ك & \multirow{2}{*}{ بناء هيكل تنظيمي يقود فريق العمل } & \multirow[b]{2}{*}{1} \\
\hline & & & & & & 1.4 & 6.8 & 24.7 & 39.7 & 27.4 & $\%$ & & \\
\hline \multirow[t]{2}{*}{11} & \multirow{2}{*}{0.001} & \multirow[t]{2}{*}{6.6} & \multirow[t]{2}{*}{75.6} & \multirow[t]{2}{*}{1.00} & \multirow[t]{2}{*}{3.78} & 1 & 6 & 22 & 23 & 21 & ك & \multirow{2}{*}{ 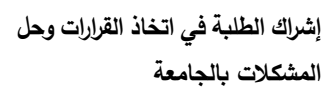 } & \multirow{2}{*}{2} \\
\hline & & & & & & 1.4 & 8.2 & 30.1 & 31.5 & 28.8 & $\%$ & & \\
\hline \multirow{2}{*}{2} & \multirow[b]{2}{*}{0.001} & \multirow{2}{*}{11.2} & \multirow{2}{*}{83.0} & \multirow{2}{*}{0.88} & \multirow{2}{*}{4.15} & 1 & 3 & 8 & 33 & 28 & ك & \multirow{2}{*}{ الفنر ثقافة تنظيمية إيجابية تحفز } & \multirow[b]{2}{*}{3} \\
\hline & & & & & & 1.4 & 4.1 & 11.0 & 45.2 & 38.4 & $\%$ & & \\
\hline \multirow[t]{2}{*}{4} & \multirow{2}{*}{0.001} & \multirow[t]{2}{*}{11.2} & \multirow[t]{2}{*}{80.5} & \multirow[t]{2}{*}{0.78} & \multirow[t]{2}{*}{4.03} & 0 & 3 & 12 & 38 & 20 & ك & خلق ثقافة تعاونية تعزز عمليات & 1 \\
\hline & & & & & & 0 & 4.1 & 16.4 & 52.1 & 27.4 & $\%$ & التعلم وتبادل الخبرات بين الطلبة & 4 \\
\hline 5 & & 9.4 & 800 & 091 & 400 & 0 & 5 & 15 & 28 & 25 & s & تهيئة المناخ الإيجابي المحفز على & \\
\hline$J$ & 0.001 & 9.4 & 00.0 & 0.91 & 4.00 & 0 & 6.8 & 20.5 & 38.4 & 34.2 & $\%$ & 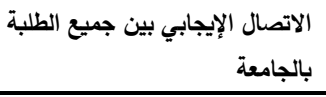 & 5 \\
\hline 7 & & 7.7 & 77.8 & 0.99 & 3.89 & 2 & 3 & 19 & 26 & 23 & s & تعزيز عمل الفريق بين الطلبة & \\
\hline 1 & 0.001 & 1.1 & 11.8 & 0.99 & 3.89 & 2.7 & 4.1 & 26.0 & 35.6 & 31.5 & $\%$ & ونشرها وتطبيقها & 6 \\
\hline 3 & & 104 & 80.8 & 0.86 & 404 & 0 & 4 & 13 & 32 & 24 & s & توفير وسائل متعددة لسهولة انتقال & \\
\hline$J$ & 0.001 & 10.4 & 00.0 & 0.00 & 4.04 & 0 & 5.5 & 17.8 & 43.8 & 32.9 & $\%$ & التعليمية المختلفة والمعرفة بين المستويات & 7 \\
\hline 6 & & 8.5 & 78.4 & 0.92 & 3.92 & 1 & 4 & 16 & 31 & 21 & ك & التقييم التنظيمي وتوجيه أنثطة & \\
\hline & 0.001 & & & & & 1.4 & 5.5 & 21.9 & 42.5 & 28.8 & $\%$ & تنظيم إدارة رأس المال الفكري بامعة لضمان استراتيجية & 8 \\
\hline 1 & & 14. & 84.7 & 0.75 & 4.23 & 0 & 0 & 14 & 28 & 31 & ك & وجود آلية واضحة لدعم وتطوير & \\
\hline 1 & 0.001 & 14.0 & 84.1 & 0.15 & 4.25 & 0 & 0 & 19.2 & 38.4 & 42.5 & $\%$ & وحفظها ونشرها & 9 \\
\hline 8 & & 70 & 77.3 & 0.93 & 3.86 & 0 & 6 & 19 & 27 & 21 & ك & بناء نظام متكامل لإدارة رأس المال & \\
\hline 0 & 0.001 & 1.7 & 11.3 & 0.93 & 3.00 & 0 & 8.2 & 26.0 & 37.0 & 28.8 & $\%$ & 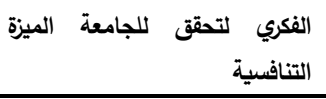 & 10 \\
\hline & & & & & & 3 & 6 & 13 & 31 & 20 & ك & استحداث آلية لحفظ الخبرات & \\
\hline 10 & 0.001 & 6.5 & 76.2 & 1.06 & 3.81 & 4.1 & 8.2 & 17.8 & 42.5 & 27.4 & $\%$ & تخرجهم & 11 \\
\hline & 0.001 & 11.4 & 79.2 & 0.72 & 3.96 & & & & & & & المتوسط الكلي & \\
\hline
\end{tabular}

يتضح من نتائج الجدول (10) أن المتطلبات التنظيمية لتطبيق إدارة رأس المال الفكري في جامعة المجمعة قد جاءت بدرجة كبيرة جداً، وبدرجة كبيرة، حيث بلغ المتوسط الحسابي العام (3.96 من 5) وهو متوسط يقع في الفئة الأولى والثانية من فئات مقياس ليكرت الخماسي، كما أن الانحراف المعياري بلغ (0.72) مما يشير إلى تجانس أفراد عينة الدراسة حول عبارات هذا المحور. 
وتفسر هذه النتيجة أهمية توافر المتطلبات التظظيمية أما بقية العبارات فقد جاءت في المراتب من الثانية لإدارة رأس المال الفكري، حيث أنه يتضمن قدرات إلى الحادية عشر من بين عبارات محور المتطلبات

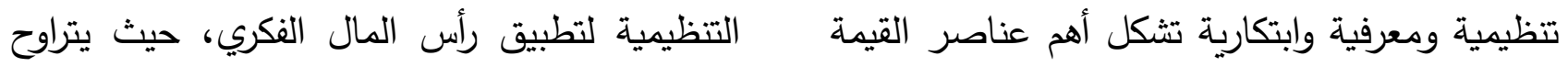

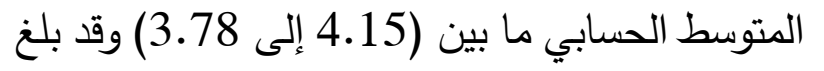
والتميز للمؤسسة التعليمية. كما ويُلحظ في الجدول أعلاه موافقة أفراد عينة الدراسة الوزن النسبي لها ما بين (83\%) إلى (75.6\%). على المتطلب (وجود آلية واضحة لدعم وتطوير وهذا ما يتوافق مع دراسة (عبد الهادي،2017م)؛

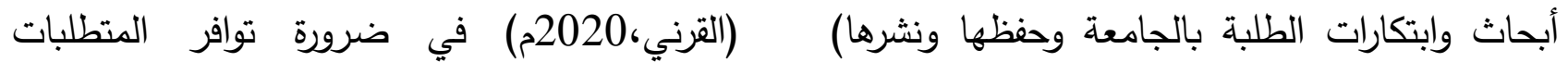
بدرجة كبيرة جداً حيث جاءت بالمرتبة الأولى من بين التتظيمية لإدارة رأس المال الفكري بدرجة كبيرة.

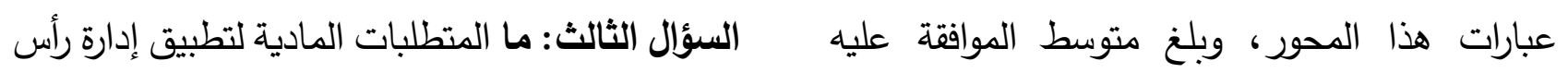
(4.23) درجة من أصل (5) درجات وهي متوسطات المال الفكري للى طلبة جامعة المجمعة من وجهة

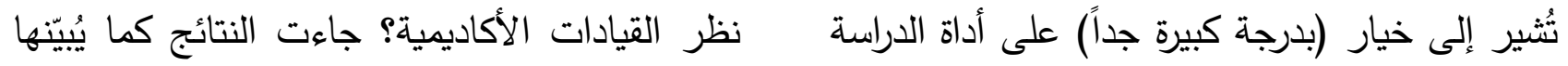

$$
\text { وبلغ الوزن النسبي للموافقة (84.7\%). }
$$

جدول رقم (11): وجهات نظر القيادات الأكاديمية حول المتطلبات المادية لتطبيق إدارة أس المال الفكري

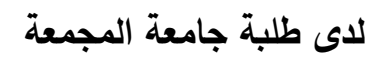

\begin{tabular}{|c|c|c|c|c|c|c|c|c|c|c|c|c|c|}
\hline 霄! & 柔. & 等 & 高 & 网 & 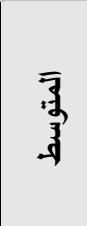 & 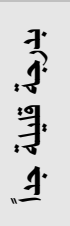 & 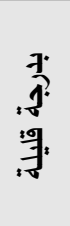 & 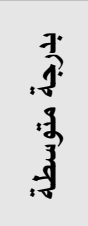 & 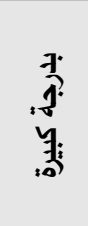 & 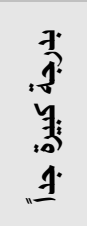 & & الع & \\
\hline \multirow[b]{2}{*}{5} & \multirow[b]{2}{*}{0.001} & \multirow[b]{2}{*}{9.6} & \multirow[b]{2}{*}{83.3} & \multirow[b]{2}{*}{1.04} & \multirow[b]{2}{*}{4.16} & 2 & 3 & 13 & 18 & 37 & كـ & \multirow{2}{*}{ 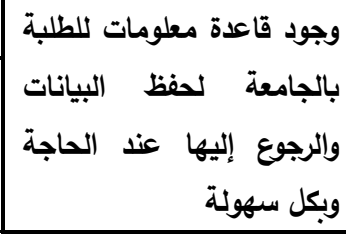 } & \\
\hline & & & & & & 2.7 & 4.1 & 17.8 & 24.7 & 50.7 & $\%$ & & 1 \\
\hline \multirow{2}{*}{1} & \multirow[b]{2}{*}{0.001} & \multirow[b]{2}{*}{13.3} & \multirow{2}{*}{86.3} & \multirow{2}{*}{0.85} & \multirow{2}{*}{4.32} & 0 & 2 & 12 & 20 & 39 & ك & \multirow{2}{*}{ والتطصيص م ميزانية لتمويل } & \\
\hline & & & & & & 0 & 2.7 & 16.4 & 27.4 & 53.4 & $\%$ & & 2 \\
\hline \multirow[b]{2}{*}{4} & \multirow[b]{2}{*}{0.001} & \multirow[b]{2}{*}{11.5} & \multirow[b]{2}{*}{83.5} & \multirow[b]{2}{*}{0.87} & \multirow[b]{2}{*}{4.17} & 0 & 2 & 16 & 23 & 32 & كى & \multirow{2}{*}{\multicolumn{2}{|c|}{ | }} \\
\hline & & & & & & 0 & 2.7 & 21.9 & 31.5 & 43.8 & $\%$ & & \\
\hline 7 & 0.001 & 7.5 & 78.4 & 1.05 & 3.92 & 2 & 4 & 19 & 21 & 27 & ك & & \\
\hline
\end{tabular}




\begin{tabular}{|c|c|c|c|c|c|c|c|c|c|c|c|c|c|}
\hline & & & & & & 2.7 & 5.5 & 26.0 & 28.8 & 37.0 & $\%$ & 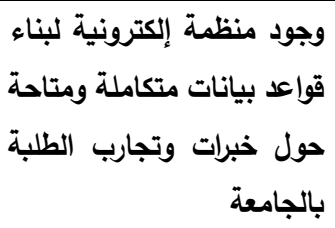 & 4 \\
\hline \multirow{2}{*}{3} & \multirow[b]{2}{*}{0.001} & \multirow[b]{2}{*}{11.0} & \multirow{2}{*}{83.6} & \multirow{2}{*}{0.92} & \multirow{2}{*}{4.18} & 1 & 2 & 13 & 24 & 33 & ك & \multirow{2}{*}{ معارفهم وخبراتهم وزملائهر على مشاركة } & \\
\hline & & & & & & 1.4 & 2.7 & 17.8 & 32.9 & 45.2 & $\%$ & & 5 \\
\hline \multirow{2}{*}{2} & \multirow[b]{2}{*}{0.001} & \multirow[b]{2}{*}{13.3} & \multirow{2}{*}{85.5} & \multirow{2}{*}{0.82} & \multirow{2}{*}{4.27} & 0 & 3 & 8 & 28 & 34 & ك & \multirow{2}{*}{ 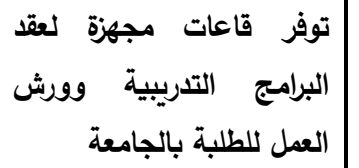 } & \\
\hline & & & & & & 0 & 4.1 & 11.0 & 38.4 & 46.6 & $\%$ & & 6 \\
\hline \multirow[b]{2}{*}{6} & \multirow[b]{2}{*}{0.001} & \multirow[b]{2}{*}{9.5} & \multirow[b]{2}{*}{81.4} & \multirow[b]{2}{*}{0.96} & \multirow[b]{2}{*}{4.07} & 0 & 5 & 16 & 21 & 31 & ك & \multirow{2}{*}{ 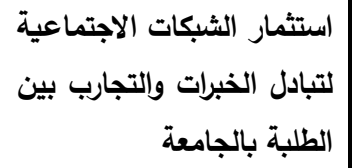 } & \\
\hline & & & & & & 0 & 6.8 & 21.9 & 28.8 & 42.5 & $\%$ & & 7 \\
\hline & 0.001 & 13.9 & 83.1 & 0.71 & 4.15 & & & & & & & المتوسط الكلي & \\
\hline
\end{tabular}

يتضح من نتائج الجدول (11) أن المتطلبات المادية لتطبيق إدارة رأس المال الفكري في جامعة المجمعة قد جاءت بدرجة كبيرة جداً، وبدرجة كبيرة، حيث بلغ المتوسط الحسابي العام (4.15من 5) وهو متوسط يقع في الفئة الأولى والثانية من فئات مقياس ليكرت الخماسي، كما أن الانحراف المعياري بلغ (0.71) مما يشير إلى تجانس أفراد عينة الدراسة حول عبارات هذا المحور . وتفسر هذه النتيجة أهمية توافر المتطلبات المادية أصل (5) درجات وهي متوسطات تُشير إلى خيار لإدارة رأس المال الفكري، حيث أن تطبيق إدارة رأس (بدرجة كبيرة جداً) على أداة الدراسة وبلغ الوزن النسبي المال الفكري يتطلب توافر الموارد المادية حيث لها للموافقة (86.3\%)، (85.5\%)على التوالي. تأثير كبير عليها، وتوافرها يسهل توافر بقية المتطلبات أما بقية العبارات فقد جاءت في المراتب من الثالثة إلى السابعة من بين عبارات محور المتطلبات المادية النازمة. لتطبيق رأس المال الفكري، حيث يتراوح المتوسط كما ويُلحظ في الجدول أعلاه موافقة أفراد عينة الدراسة الحسابي ما بين (4.18 إلى 3.92) وقد بلغ الوزن على المتطلبات (تخصيص ميزانية لتمويل ودعم النسبي لها ما بين (83.6\%) إلى (78.4\%). وهذا مشاريع البحث العلمي والتطوير للطلبة بالجامعة، ما يتوافق مع دراسة (عبد القبلي،2015م)؛ وتوفر قاعات مجهزة لعقد البرامج التدربية وورش العمل للطلبة بالجامعة) في المراتب من الأولى إلى (القرني،2020م) في ضرورة توافر المتطلبات المادية الثانية من بين عبارات محور المتطلبات المادية لإدارة رأس المال الفكري بدرجة كبيرة. لتطبيق رأس المال الفكري بالجامعة، وتراوح متوسط موافقة على ذلك ما بين (4.32 إلى 4.27$)$ 
اختبار تحليل التباين الأحادي (One Way ANOVA) للتعرف على ما إذا كانت هناك فروق ذات دلالة إحصائية بين استجابات القيادات الأكاديمية باختلاف

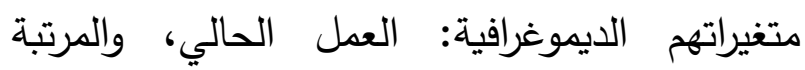
وسنوات الخدمة عند مستوى دلالة (0.05) فأقل والجدول التالي يوضح ذلك:

جدول رقم (12)

يوضح مدى الاختلاف بين القيادات الأكاديمية بجامعة المجمعة حول متطلبات تطبيق إدارة رأس المال الفكري لاى طلاب

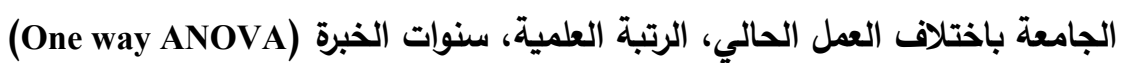

\begin{tabular}{|c|c|c|c|c|c|c|}
\hline مستوى الدلالة & قيمة ف & المربعات & 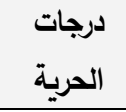 & المبربعات & مصدر التباين & المحور \\
\hline \multirow{3}{*}{0.904} & \multirow{3}{*}{0.189} & .104 & 3 & .312 & بين المجموعات & \multirow{3}{*}{ ألس المال الفكري البشرية لتطبيق إدارة } \\
\hline & & .551 & 69 & 38.021 & داخل المجموعات & \\
\hline & & & 72 & 38.333 & المجموع & \\
\hline \multirow{3}{*}{0.888} & \multirow{3}{*}{0.212} & .114 & 3 & .342 & بين المجموعات & \multirow{3}{*}{ إلدارة رأس المال الفكري } \\
\hline & & .539 & 69 & 37.178 & داخل المجموعات & \\
\hline & & & 72 & 37.520 & المجموع & \\
\hline \multirow{3}{*}{0.583} & \multirow{3}{*}{0.654} & .337 & 3 & 1.010 & بين المجموعات & \multirow{3}{*}{ 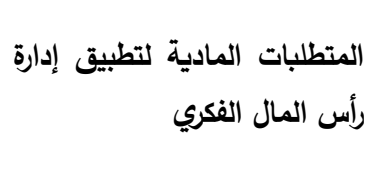 } \\
\hline & & .515 & 69 & 35.511 & داخل المجموعات & \\
\hline & & & 72 & 36.521 & المجموع & \\
\hline \multirow{3}{*}{0.782} & \multirow{3}{*}{0.360} & .153 & 3 & .458 & بين المجموعات & \multirow{3}{*}{ جميع متطلبات لتطبيق إدارة رأس } \\
\hline & & .424 & 69 & 29.226 & داخل المجموعات & \\
\hline & & & 72 & 29.684 & المجموع & \\
\hline مستوى الدلالة & قيمة ف & المربعات & ل الحرية & المربعات & مصدر التباين & المحور \\
\hline \multirow{3}{*}{0.909} & \multirow{3}{*}{0.181} & .100 & 3 & .299 & بين المجموعات & \multirow{3}{*}{ أس المتطلبات البثرية لتطبيق إدارة } \\
\hline & & .551 & 69 & 38.034 & داخل المجموعات & \\
\hline & & & 72 & 38.333 & المجموع & \\
\hline \multirow{3}{*}{0.637} & \multirow{3}{*}{0.569} & .302 & 3 & .907 & بين المجموعات & \multirow{3}{*}{ إلدارة رأس المال الفكري التظيمية لتطبيق } \\
\hline & & .531 & 69 & 36.614 & داخل المجموعات & \\
\hline & & & 72 & 37.520 & المجموع & \\
\hline \multirow{2}{*}{0.800} & \multirow{2}{*}{0.335} & .175 & 3 & .524 & بين المجموعات & \multirow{2}{*}{ 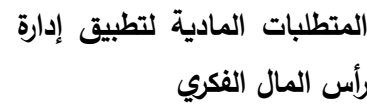 } \\
\hline & & .522 & 69 & 35.996 & داخل المجموعات & \\
\hline
\end{tabular}




\begin{tabular}{|c|c|c|c|c|c|c|c|}
\hline & & & & 72 & 36.521 & المجموع & \\
\hline \multirow{3}{*}{0.812} & \multirow{3}{*}{\multicolumn{2}{|c|}{0.318}} & .135 & 3 & .405 & بين المجموعات & \multirow{3}{*}{ جميع متطلبات لتطبيق إدارة رأس } \\
\hline & & & \multirow[t]{2}{*}{.424} & 69 & 29.279 & داخل المجموعات & \\
\hline & & & & 72 & 29.684 & المجموع & \\
\hline مستوى الدلالة & قيمة (ت) & الحرية & الانحراف & المتوسط & العدد ال الع & المرتبة & المحور \\
\hline \multirow{2}{*}{0.439} & \multirow{2}{*}{0.778} & \multirow{2}{*}{71} & 0.62 & 3.71 & 14 & أستاذ مشاررك فأعلى & \multirow{2}{*}{ ألس المال الفكري البشرية لتطبيق إدارة } \\
\hline & & & 0.76 & 3.88 & 59 & أستاذ مساعد & \\
\hline \multirow{2}{*}{0.318} & \multirow{2}{*}{1.006} & \multirow{2}{*}{71} & 0.86 & 3.79 & 14 & أستاذ مشارك فأعلى & \multirow{2}{*}{ إلدارة رأس المال الفكري } \\
\hline & & & 0.69 & 4.00 & 59 & أستاذ مساعد & \\
\hline \multirow{2}{*}{0.630} & \multirow{2}{*}{0.483} & \multirow{2}{*}{71} & 0.62 & 4.07 & 14 & أستاذ مشارك فأعلى & \multirow{2}{*}{ 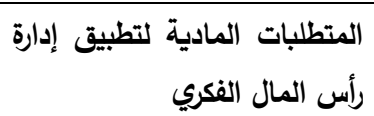 } \\
\hline & & & 0.74 & 4.17 & 59 & أستاذ مساعد & \\
\hline \multirow{2}{*}{0.383} & \multirow{2}{*}{0.879} & \multirow{2}{*}{71} & 0.65 & 3.86 & 14 & أستاذ مشارك فأعلى & \multirow{2}{*}{ جميع متطلبات لتطبيق إدارة رأس } \\
\hline & & & 0.64 & 4.03 & 59 & أستاذ مساعد & \\
\hline
\end{tabular}

(P>0.05) (دالة عند مستوى دلالة"

أظهرت النتائج التي بالجدول أعلاه أنه لا توجد فروق أهم نتائج البحث: ذات دلالة إحصائية بين وجهات نظر القيادات أن جميع متطلبات تطبيق إدارة رأس المال الفكري الأكاديمية بجامعة المجمعة حول المتطلبات -البشرية بالجامعة (متطلبات بشرية، متطلبات تنظيمية، والتتظيمية والمادية والمتطلبات مجتمعة - لتطبيق متطلبات مادية) هام توافرها بدرجة كبيرة.

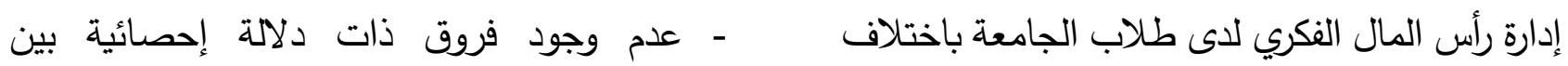
متوسطات استجابات أفراد عينة الدراسة حول أهمية توافر جميع متطلبات تطبيق إدارة رأس المال الفكري بالجامعة تعزى لمتغيرات (العمل الحالي، الرتبة

$$
\text { توصيات البحثة، سنوات الخبرة). }
$$

4. على الجامعة تبني سياسات لتوجيه المعرفة الضمنية الكامنة في عقول طلابها لخلق مجالاً مفتوحاً للابتكار والابداع لتطوير الجامعة ومؤسسات (العمل الحالي، الرتبة العلمية، سنوات الخبرة)، إذ بلغت قيمة ت المحسوبة (0.360-0.318 0.879)، وتراوح مستوى الدلالة ما بين (0.782 0.812 - 0.383) وهي قيم أكبر من (0.05)، وهي غير دالة إحصائياً. أي أن جميع القيادات الاكاديمية باختلاف عملهم الحالي والرتبة العلمية وسنوات الخبرة يتفقون جميعاً على أن المتطلبات البشرية والتظيمية والمادية لها اهمية بدرجة كبيرة في تطبيق إدارة رأس المال الفكري لدى طلاب الجامعة. ل 


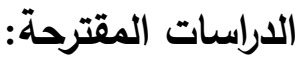

1.إجراء دراسة مماثلة تثكل كافة الجامعات السعودية لتحديد متطلبات تطبيق إدارة رأس المال الفكري لديها في ضوء تحقيق رؤية 2030م. 2.معوقات تطبيق إدارة رأس المال الفكري لدى

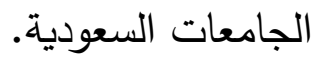

\section{المراجع}

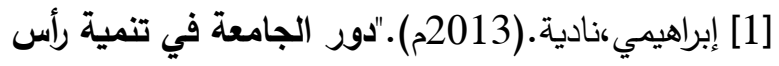

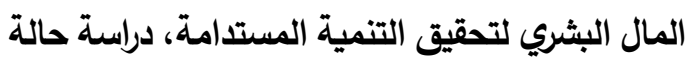
جامعة المسيلة". رسالة ماجستير غير منشورة، كلية العلوم الاقتصادية، جامعة فرحات عباس:الجزائر [2] آل سعيدي،يحيى.(2017م)."إدارة رأس المال الفكري

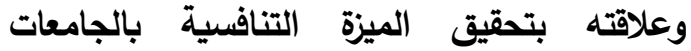
السعودية رؤية مستقبلية".رسالة دكتوراه غير منشورة، وبنات جامعة الملك خالد: أبها [3] [3/معة المجمعة، 2020م

https://www.mu.edu.sa/ar/content/\%D8\%A7 \%D9\%84\%D8\%AA\%D8\%A7\%D8\%B $1 \% \mathrm{D} 9 \% 8 \mathrm{~A} \% \mathrm{D} 8 \% \mathrm{AE}$

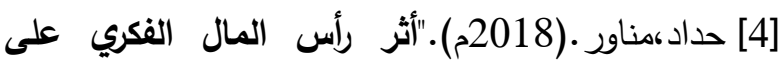
تنمية وتحسين كفاءة الموارد البشرية".بحث منشور في مجلة رماح للبحوث والدراسات.ع26.مركز البحث وتطوير الموراد البشرية:رماح [5] الخضري، مها.(2015م)."واقع إدارة رأس المال الفكري بالجامعات الفلسطينية الخاصة في قطاع غزة".رسالة ماجستير غير منشورة، برنامج الدراسات العليا المشترك بين أكاديمية الإدارة والسياسة وجامعة الإنية

$$
\text { الأقصى :غزة }
$$

[6]"الخطة الاستراتيجية الثالثة لجامعة المجمعة 20202025م استدامة التميز".جامعة المجمعة:المجمعة
5. اعتماد نظام حوافز ومكافآت تشجع الطلبة على مشاركة معارفهم وخبراتهم مع زملائهم والجامعة والمجتمع. 6. على الجامعة تقييم استراتيجيات المنافسين على المستوى المحلي والاقليمي والعالمي وما لديهم من

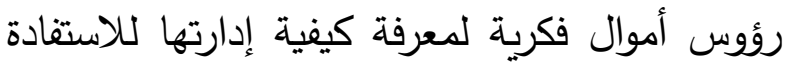
من خبراتهم. - - من 7. على الجامعة استثمار وتفعيل رأس المال الفكري الذي يمتلكه طلابها بعد التعرف عليه وتتييمه واستيعابه من خلال تطوير هياكلها لإكسابها مصادر

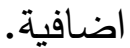

8. على الجامعة تهيئة البنية التحتية من تجهيزات ومعامل وقواعد بيانات متكاملة تساعد الطلاب المبدعين على إطلاق ابداعاتهم ونشر أفكارهم عبر الشبكات الاجتماعية لتبادل الخبرات والتجارب بين الطلبة بالجامعة، واستخدام المنصات الإلكترونية

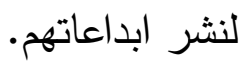
9. على إدارة ضمان الجودة بالجامعة الإشراف على ابداعات وبحوث الطلاب وتتييمها وتحسين نوعيتها للاستفادة منها في تطوير الاداء بالجامعة، وتثجيعهم على المشاركة بالمؤتمرات المحلية والعالمية. 10. العمل على ازالة كافة المعوقات والمشكلات التي تعوق تطبيق ادارة راس المال الفكري لدى

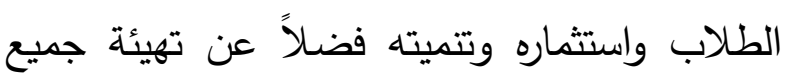
العوامل والظروف الملائمة التي تهيء إدارته. 
[13] عبدالسلامهبندي؛ وعلة،مراد.(2011م) ."دور رأس المال الفكري (المعرفي) في خلق الميزة التنافسية في ظل

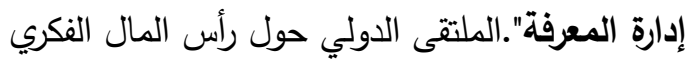

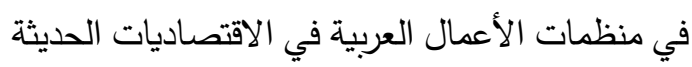
بالجزئر •جامعة الثلف،13-14 ديسمبر .

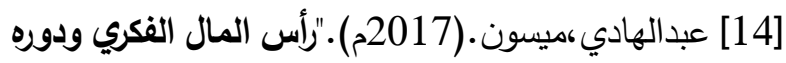

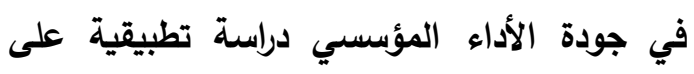
برنامج التربية والتعليم بوكالة غوث وتثثغيل اللاجئين

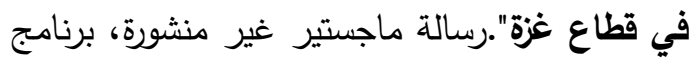
الدراسات العليا المشترك بين أكاديمية الإدارة والسياسة للدراسات العليا وجامعة الأقصى:غزة

[15] العجمي،حجاج؛ وبدارنة، حازم.(2010م)."دور إدارة رأس المال الفكري في دعم المزايا التنافسية

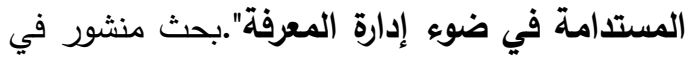
مؤتمر تطوير رأس المال الفكري، وزارة الثؤون الإسلامية،18-20 يناير :الكويت

[16] العصفور،صالح.(2012م)."سياسات التنافسية".بحث الإدية

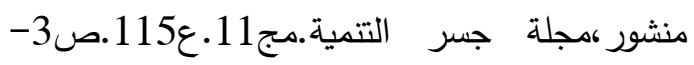
14:الكويت

غبور،أماني.(2015م)."تصور مقترح لإدارة رأس المال

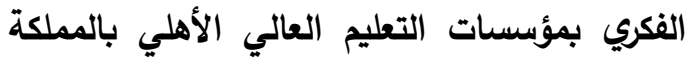
العربية السعودية".رسالة ماجستير غير منشورة.كليات

$$
\text { الثرق العربي:الرياض الثبل }
$$

[17] القبلي،منال.(2015م)."واقع إدارة رأس المال الفكري الفياض

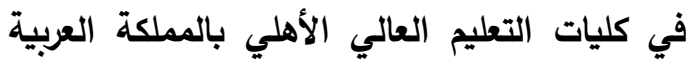
السعودية".رسالة ماجستير غير منشورة،كليات الثرق المقات

$$
\text { العربي:الرياض }
$$

[18] القرشي،مسعود.(2011م)."متطلبات تنمية رأس المال

الفكري بالجامعات السعودية في ضوء الاتجاهات

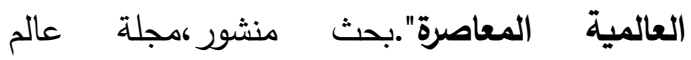

$$
\text { التربية.ع12.ص15-79 المالمية }
$$

[7] الراثدي،حامد.(2017م)."إدارة رأس المال الفكري

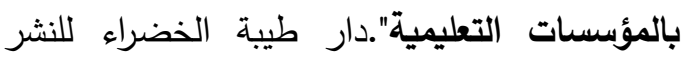
والتوزيع:مكة المكرمة

[8] الراشدي،حامد.(2019م)."واقع إدارة رأس المال الفكري بككاتب التعليم بمكة المكرمة من وجهة نظر المشرفين التربويين".بحث منشور في مجلة القراءة والمعرفة.جامعة عين شمس،كلية التربية، الجمعية فئلية

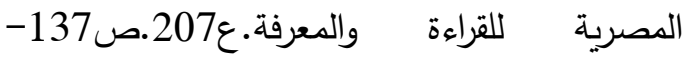
265 :مصربة

[9] الزهيري،إبراهيم.(2012)."رأس المال الفكري:الخيار

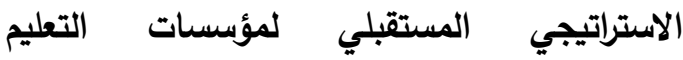
العالي".المؤتمر العلمي السنوي العربي الرابع لكلية التربية النوعية جامعة المنصورة(إدارة المعرفة وإدارة رأس المال الفكري في مؤسسات التعليم العالي في التئية مصر والوطن العربي)،مج1، جامعة المنصورة:كلية

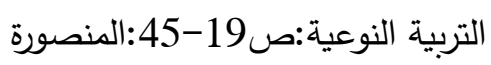

[10] الثمري،عبدالله.(2013م)."تصور مقترح لإدارة رأس التس المال الفكري بالمؤسسات التعليمية في ضوء مدخل إدارة المعرفة".مجلة كلية التربية،جامعة

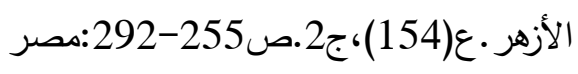

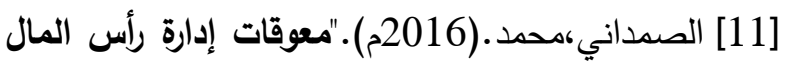
الفكري بمدارس التعليم العام بمحافظة الليث من وجهة نظر قادتها".بحث منشور في مجلة القراءة والمعرفة. ع181.ص14-44.جامعة عين شمس، كلية التربية، الجمعية المصرية للقراءة والمعرفة.

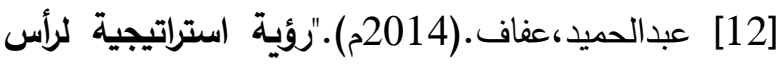
المال الفكري ودوره في تحقيق الميزة التنافسية دراسة ميدانية".بحث منشور في مؤتمر رأس المال الفكري العربي نحو رؤية استراتيجية جديدة للاستثمار والتطوير.بالتعاون مع معد الإدارة العامة بسلطنة عمان.ج1.ص121-150:عمان 
[26] ويح،محد.(2013م)."متطلبات تطوير رأس المال الفكري لتحقيق الميزة التنافسية للجامعات دراسة ميدانية على جامعة بنها".بحث منشور ،مجلة التربية

$$
\text { بنها.ع24.ص239-244 }
$$

[27] Corcoles، Yolanda Ramirez. (2013)."Intellectual capital management and reporting in European higher education institutions،"Business Source Complete، 9 (1): p.p1-19.

[28]Rodrigues, Helena, Gupta, Praveen\& Carlson, Robert. (2015). "Exploiting Intellectual Capital for Economic Renewal", International Journal of Innovation Science, Vol.(7), No

\section{الملاحق}

$$
\text { بسم الله الرحمن الرحيم }
$$

سعادة القائد الأكاديمي بجامعة المجمعة/ وفقه الله السـلام عليكم ورحمة الله وبركاته .. وبعد:

تقوم الباحثة بإعداد دراسة علمية بعنوان: (متطلبات تطبيق إدارة رأس المال الفكري لاى طلاب جامعة المجمعة من وجهة

$$
\text { نظر القيادات الأكاديمية). }
$$

ويقصد بالقائد الأكاديمي: أعضاء هيئة التدريس بجامعة

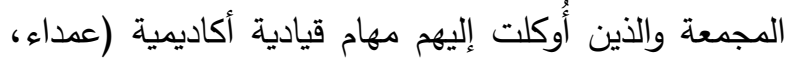

$$
\text { وكلاء، رؤساء أقسام، منسقات أقسام) بالجامعة. }
$$

وتعني إدارة رأس المال الفكري: الممارسات والعمليات التي تتم داخل جامعة المجمعة لتوظيف مهارات وخبرات ومعارف الطلبة داخلها، من خلال التجربة العملية والابتكار ، والاستمرار

$$
\text { لتحقيق التميز التتافسي لديها. }
$$

ولتحقيق أهداف الدراسة قامت الباحثة ببناء استبانة، وتتكون

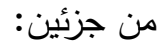

[19] قرني ،أسامة؛ إبراهيم.مرعي.(2012م)."إدارة رأس المال الفكري بالجامعات المصرية كمدخل لتحقيق قدرتها التنافسية - مقصور التربية.ع38.ص323-234.

[20] قرني، أسامة؛ والعيقي، إبراهيم.(2012م)."إدارة رأس المال الفكري بالجامعات المصرية كمدخل لتحقيق قدرتها التنافسية تصور مقترح ".بحيث منشور في مجلة التربية الجمعية المصرية للتربية المقارنة والإدارة التعليمية.ع35:مصر

[21] القرني،حسن. (2020م)."استراتيجية مقترحة لإدارة رأس المال الفكري بالجامعات السعودية في ضوء اقتصاد المعرفة".رسالة دكتوراه غير منشورة، كلية التربية، جامعة الإمام محمد بن سعود الإسلامية:الرياض

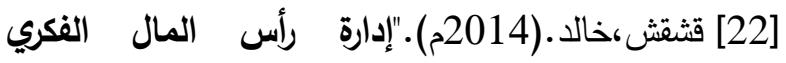
وعلاقته في تعزيز الميزة التنافسية دراسة تطبيقية على الجامعات الفلسطينية بطاع غزة".رسالة ماجستير غير منشورة.كلية الاقتصاد والعلوم الإدارية،جامعة الأزهر :غزة محمد،أشرف السعيد؛ الزايدي،أحمد.(2015م)." مجتمعات التعلم المهنية كمدخل لتنمية رأس المال الفكري (دراسة مستقبلية).مجلة كلية التربية بينها".ع56 (3).ص 70 70-141.

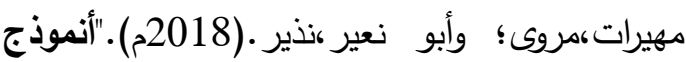
تربوي مقترح لتطوير التعليم الجامعي وفقًا لرأس المال الفكري".بحث منشور بمجلة العلوم التربوية، بالجامعة الأردنية.مج45.ص4416-443:الأردن [25] الهلالي،الشربيني.(2011م)."إدارة رأس المال الفكري وقياسه وتنميته كجزء من إدارة المعرفة في مؤسسات التعليم العالي".بحث منشور في مجلة بحوث التربية النوعية.ع22.كلية التزبية النوعية، 


\begin{tabular}{|c|c|c|c|c|c|c|}
\hline غير موافقة بشدة & غير موافقة & موافقة & موافقة بدرجة متوسطة & موافقة بدرجة كبيرة & العبارة & ? \\
\hline & & & & $\checkmark$ & & \\
\hline
\end{tabular}

المجمعة من وجهة نظر القيادات الأكاديمية، ونظراً لأهمية رأيكم في نتائج الدراسة أرجو التفضل بقراءة الاستبانة بتمعن ثم الإجابة بوضع إشارة أمام العبارة التي ترونها مناسبة من وجهة نظركم كما في المثال التالي: - (التي najla.omery.5@hotmail.com البربد الإكتروني: أولاً: البيانات الأولية: 1- - 1 - العمل الحالي: 0 0 وكيل / وكيلة 0 o منسقة قسم 2- 2 - الرتبة العلمية: O أستاذ o أستاذ مشارك o أستاذ مساعد

المحاور/ متطلبات تطبيق إدارة رأس المال الفكري لدى طلاب جامعة المجمعة من وجهة نظر القيادات

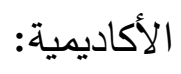

برجاء وضع علامة (لا) أمام الخيار الأي ترونه مناسباً للعبارة المقابلة في الجدول التالي:
الجزء الأول: البيانات العامة، وهي بيانات مهمة أرجو من

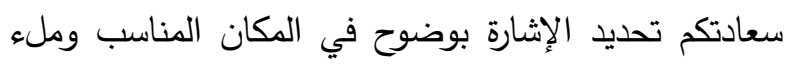
الفراغات بالمعلومات المطلوبة. الجزء الثاني: العبارات المتعلقة بتحديد متطلبات تطبيق إدارة رأس المال الفكري لدى طلبة جامعة وتؤكد الباحثة سرية المعلومات التي تدلون بها وأنها لن تستخدم إلا فيما يحقق أهداف الدراسة مع إجراء الإجابة عن كافة العبارات.

شاكرة لكم تعاونكم متمنية لكم دوام التوفيق والسداد وجزاكم الله خيراً، ، 6 وتأمل الباحثة منكم التكرم بإعادة الاستبانة بعد تعبئتها - عاجلاً قدر الإمكان - على العنوان التالي: الباحثة/ د. نجلاء عمر صالح العُمري جامعة الإمام محمد بن سعود الإسلامية- كلية التربيةقسم الإدارة والتخطيط التربوي الجوال: 0506165152

3- سنوات الخبرة الوظيفية :

o أقل من خمس سنوات 0 من 5 إلى أقل من 10سنة 0 من 10الى اقل من 15 سنة o أكثر من 15 سنة 


\begin{tabular}{|c|c|c|c|c|c|c|}
\hline بلرجة قليلة & قبليلة & متوسطة & بل برجة كبيرة & بلبرجة كبيرة جباً & العبــــــارة & b \\
\hline \multicolumn{7}{|c|}{ المحور الأول/ المتطلبات البشريـة } \\
\hline & & & & & لكسب الخبرات وجت التنميـة المهنيـة للطلبـة بـالجـامعـة & .1 \\
\hline & & & & & 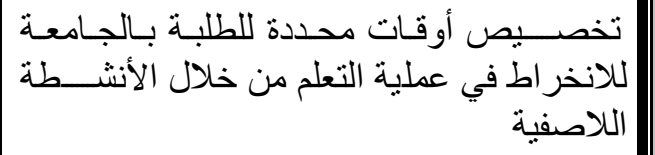 & .2 \\
\hline & & & & & مستمر عن طريق الطلبة بالجامعة على المستجات الدوريةت بشـكل & .3 \\
\hline & & & & & خبر تحفيز الطلبـة بـالجـامعـة لإظهار مـا لديهم من & .4 \\
\hline & & & & & تحسين الأداء بالجامعة الخبر اكيــة لــدى الطلبـة في & .5 \\
\hline & & & & & 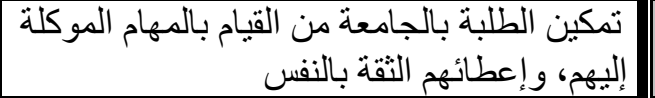 & .6 \\
\hline & & & & & 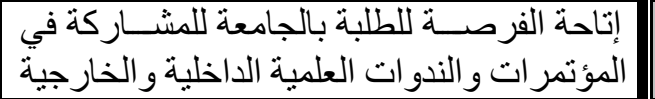 & .7 \\
\hline & & & & & 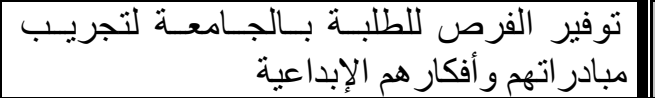 & .8 \\
\hline & & & & & إلثاني/ المنطلبات التنظيمية & 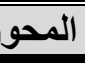 \\
\hline & & & فرديـة إلى & 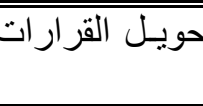 & جماعية هيكل تنظيمي يقود فريق العملـل الطلابي & .1 \\
\hline & & & & 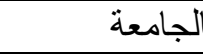 & إثر الك الطلبة في اتخاذ القرار ات وحل المشكلات & .2 \\
\hline & & & ي للطلبة & 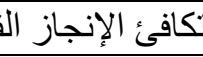 & نشر ثقافة تنظيمية إيجابية تحفز الإبداع و الابتكار & .3 \\
\hline & & & & ات بين الطلبة & خلق ثقافة تعاونية تعزز عمليات التعلم وتبادل الخب & .4 \\
\hline & & & 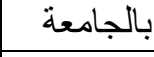 & 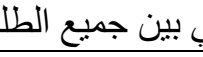 & تهيئة المناخ الإيجابي المحفز على الاتصال الإيجا & .5 \\
\hline & & & وتطبيقها & 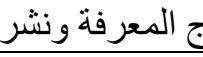 & تعزيز عمل الفريق بين الطلبة بالجامعة الداعم لإنت & .6 \\
\hline & & & 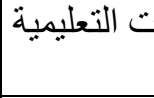 & 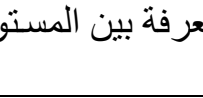 & المختلفة وسـائل متعددة لسـهولة انتقال المعلومات و الّ & .7 \\
\hline & & & 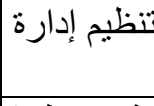 & 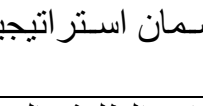 & 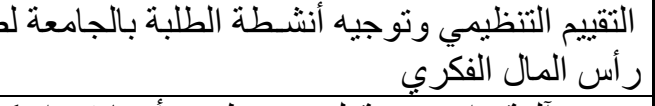 & .8 \\
\hline & & & جة وحفظها & 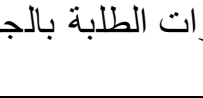 & ونشر ها آلية و اضـــحة لاعم وتطوير أبحاث و ابتك & .9 \\
\hline & & & 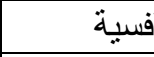 & ل الجامعة الميزة ال & بناء نظام متكامل لإدارة ر أس المال الفكري لتحقق & .10 \\
\hline & & & & ل لمتوقع تخرجهم & استحداث آلية لحفظ الخبر ات التر اكمية لدى الطلبة & .11 \\
\hline
\end{tabular}




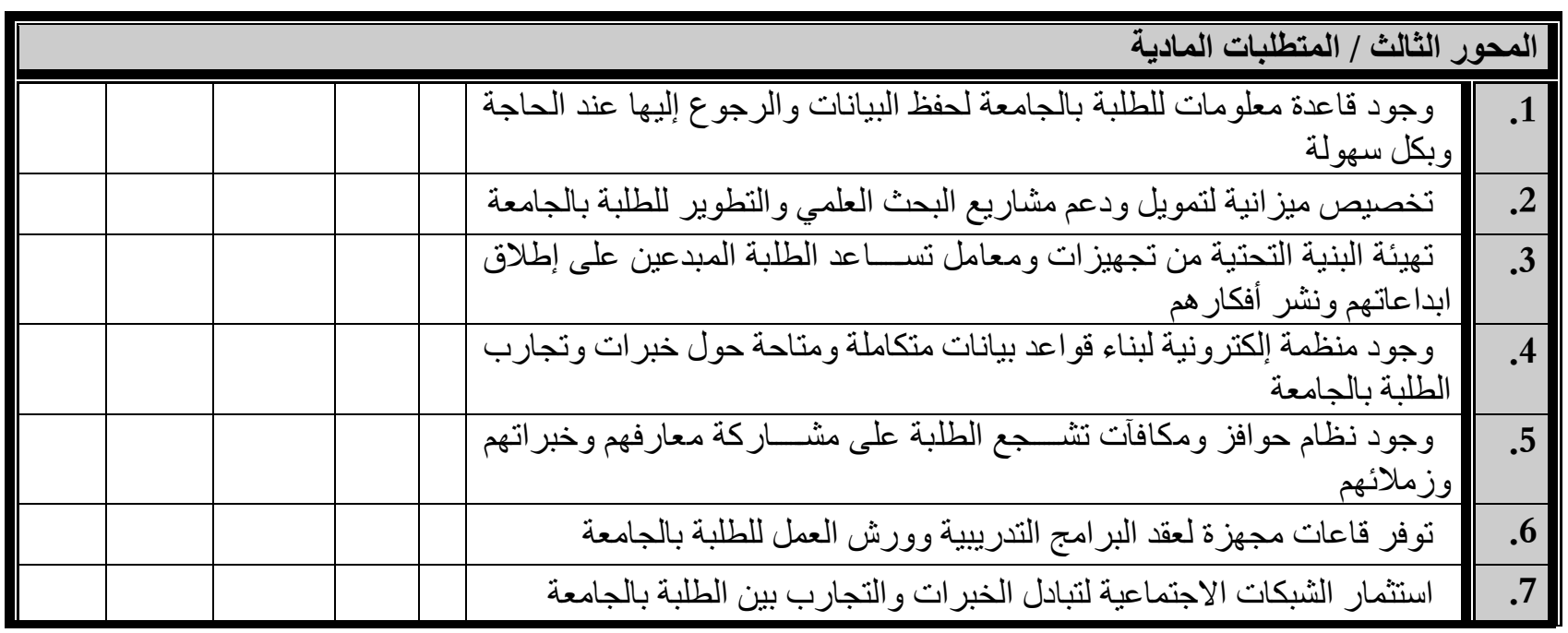




\title{
Requirements for the application of intellectual capital management among students of Majmaah University from the point of view of academic leaders
}

\author{
Dr. Najla Omar Saleh Al-Omari \\ Assistant Professor of Administration and Educational Planning \\ Imam Muhammad bin Saud Islamic University - \\ College of Education - Department of Educational Administration and \\ Planning - Kingdom of Saudi Arabia \\ e-mail: noalomary@imamu.edu.sa
}

Summary. this research aims to identify the human, organizational and material requirements for the application of intellectual capital management among the students of Majmaah University from the point of view of academic leaders. To achieve the objectives of the research, the researcher used the descriptive survey method, and the questionnaire was a tool for collecting data, and it was distributed to the study population of (73) leaders. The study reached a number of results, the most prominent of which are:

- That all the requirements for the Implementation of intellectual capital management at the university (human requirements, organizational requirements, material requirements) are highly significant.

- The absence of statistically significant differences between the averages of the respondents of the study sample on the importance of the availability of all requirements for the Implementation of intellectual capital management at the university due to variables (current work, academic rank, years of experience). The study recommended:

1. The university must invest and activate the intellectual capital that its students possess after identifying, evaluating and assimilating it through developing its structures to gain additional resources.

2. The University's Quality Assurance Department shall supervise, evaluate and improve students 'innovation and research in order to benefit from them in developing the university's

performance, and encourage them to participate in local and international conferences.

3. Work to remove all obstacles and problems that hinder the Implementation of intellectual capital management of students, its investment and development, as well as the creation of all appropriate factors and conditions that prepare its management.

Keywords: intellectual capital - intellectual - capital - university - Majmaah - requirements 